\title{
Advances of Nanotechnology in the Stem Cells Research and Development
}

\author{
Jiajia Ji, Jing Ruan, Daxiang Cui*
}

\begin{abstract}
Department of Bio-Nano-Science and Engineering, National Key Laboratory of Nano/Micro Fabrication Technology, Key Laboratory for Thin Film and Microfabrication of Ministry of Education, Institute of Micro-Nano Science and Technology, Shanghai Jiao Tong University, Shanghai200240, China
\end{abstract}

*Corresponding authors. Email: dxcui@sjtu.edu.cn

\begin{abstract}
In decades, stem cell nanotechnology has become a new promising field for stem cell research and development. So, stem cell nanotechnology has attracted lots of researchers' attention and made great progress. The unique properties of nanomaterials and nanostructures which applied in the fundamental research of stem cell-based therapies have been recognized. Nanomaterials and nanotechnology have been highlighted as promising candidates for efficient control over proliferation and differentiation of stem cells, revolutionizing the treatment of neurodegenerative disorders, neuroprotection in traumatic brain injury, improving the osteospecific differentiation and function, tissue engineering scaffold, dental implant application, drug delivery, gene therapy and cell imaging or tracking. Here we summarize the main progress in this field, explore the application prospects in injuries, diseases, regenerative medicine, etc. and discuss the methods and challenges with the aim of improving application of nanotechnology in the stem cell research and development.
\end{abstract}

Keywords: Nanomaterials; Nanostructure; Stem cells; Imaging; Therapy

Citation: J. Ji, et al. Advances of nanotechnology in the stem cells research and development. Nano Biomed Eng. 2010, 2(1), 6789. DOI: $10.5101 /$ nbe.v2i1.p67-89

\section{Introduction}

Stem cell nanotechnology, referring to the application of nanotechnology in stem cell research and development, has emerged as a new promising field [13]. Stem cells are cells found in most, if not all, multicellular organisms. They are characterized by the ability to renew themselves through mitotic cell division and differentiating into a diverse range of specialized cell types. They exist mainly in the areas such as muscle, blood, bone marrow, skin and organs like the brain and liver, etc. [4-7]. Stem cells are divided into two types of embryonic stem cells (ESCs) and adult stem cells. ESCs are pluripotent stem cells derived from the inner cell mass of the blastocyst, an early-stage embryo. Adult stem cells are not pluripotent but multipotent, found throughout the body after embryonic development, that multiply by cell division to replenish dying cells and regenerate damaged tissues [8-9]. Since Evans, et al. [10] firstly reported to isolate embryonic stem cells in 1981, stem cell research have become a hot spot and provide a new application prospects for diseases, injuries and regenerative medicine [11]. Especially human induced pluripotent stem cells (ips) were successfully established in 2007; the heartening report attracted the world's eyes and brought new hope for stem cell-based therapy [12-15]. However, several obstacles must be overcome prior to their therapeutic application can be realized, which include to develop advanced technology to deeply understand and control microenvironmental signals and novel methods to track and guide transplanted stem cells to realize controllable proliferation and differentiation [16-18]. Up to date, the control over the proliferation and differentiation of stem cells is still a challenging task.

The emergence of nanotechnology brings new opportunities to stem cells research and development. Nanotechnology is the study of the controlling of matter on an atomic and molecular scale. Generally nanotechnology deals with structures of the size 100 nanometers or smaller in at least one dimension, and 
involves developing materials or systems within that size [19-20]. Such materials and systems can be designed to exhibit uniquely physical, chemical and biological properties. As we all know that the nanomaterials own four basic effects including small size effects, surface effects, tunnel effects and quantum size effects. Ultimately these effects can bring new technological opportunities as well as new challenges [21-23]. For example, nanomaterials have been highlighted as promising candidates for improving traditional tissue engineering materials. Importantly, nanomaterials exhibit superior cytocompatible, mechanical, electrical, optical, catalytic and magnetic properties compared to conventional (or micron structured) materials, which provide exciting alternative materials to finally solve the numerous problems associated with traditional implants. The application of nanomaterials and nanotechnology in stem cell research and development exhibits attractive technological prospects, which takes a new chance to solve current problems that stem cell research and development meets. In particular, the effects of structure and properties of nanomaterials on the proliferation and differentiation of stem cells have become a new interdisciplinary frontier in regeneration medicine and material science [24-25], which exhibit attractive application prospects for tissue engineering and regenerative medicine to develop biological substitutes which are used to restore, maintain, or improve damaged tissue and organ functionality [26].

Here we summarize the main advances of stem cell nanotechnology over the past few years, explore the application prospects in injuries, diseases, regenerative medicine, etc. and discuss the issues, approaches and challenges with the aim of improving application of nanotechnology in the stem cell research and development.

\section{Advance of nanotechnology in stem cell research and development}

In recent several years, with the development of nanotechnology, the application of nanotechnology in stem cell research and development has made considerable progress. For example, magnetic nanoparticles with the excellent magnetic properties have been used to isolate, sort and track stem cells [27], quantum dots as fluorescent probes have been used to label and track stem cells [28], nanomaterials such as carbon nanotubes(CNTs) [29], fluorescent CNTs [30] and dendrimers [31] have been used to deliver gene or drugs into stem cells. Nanomaterials with unique nanostructures can be designed to regulate proliferation and differentiation of stem cells [32], nanomaterialbased scaffolds for tissue engineering have been designed, fabricated and explored for application in the injuries [33]. All these advances accelerate the stem cell-related research and development.

\subsection{Stem cell nanotechnology for cell isolation}

Magnetic nanoparticles(MNPs), as shown in Figure.1, because of their superparamagnetic property, have broad application prospects in the terms of thermotherapy [33], magnetic resonance imaging(MRI) [34], tissue and organ repair [35], immunoassay [36], drug/gene delivery [37], cell separation and purification [38], etc. A single component of the stem cell is needed in stem cell therapy. So how to isolate the kind of stem cells we need from a mixture of a variety of cells in a low-cost, efficient and convenient mode is a big challenge. So far some studies have reported that magnetic nanoparticles can directly label and then isolate stem cells by magnetic force or flow cytometry. For example, Jing, et al. [39] reported that they successfully isolated and enriched peripheral blood progenitor cells (PBPCs) from human blood circulation with the use of magnetic nanoparticles combined with $\mathrm{Cd} 34$ antibody. They tested CD34+ cell by immunomagnetic labeling and isolated them using the continuous quadrupole magnetic flow sorter (QMS).Seven commercial progenitor cell labeling kits were assessed by measuring magnetophoretic mobility of KG-1a cell line, a high CD34 expression cell line, with the use of the cell tracking velocimeter (CTV). The commercial CD34 progenitor cell isolation kits from Miltenyi Biotec and Bergisch Gladbach were used to purify the progenitor cells from eleven fresh samples and eleven cryopreserved clinical leukapheresis samples derived from different donors. Results showed that the KG-1a cells were strongly labelled and isolated with a purity of $60-96 \%$, an enrichment rate of $12-16 \%$ and a throughput of (1.7-9.3) $\mathrm{x} 10^{4}$ cells/s. These data remain well within the clinical effective range. So the isolated CD34 progenitor cells can be effectively used in targeted patient therapy.

\subsection{Stem cell nanotechnology for molecular imaging and tracing}

The latest studies found that nanoparticles such as quantum dots, magnetic nanoparticles and gold nanorods can be used as markers for imaging and tracing of stem cells [40-43]. Quantum dots, because of their unique optical properities, have been increasingly improved in cellular imaging [44], immunoassays [45], DNA hybridization [46], and optical barcoding [47] and so on. With the advances in technology, quantum dots gradually provide a new technological platform for bioanalytical sciences and biomedical engineering. Ohyabu, et al. [48] reported that quantum dots could conjugate with an antibody to form composites, which can finally labeled MSCs cells by internalized. These kind of labeled MSCs underwent normal adipocyte, osteocyte, and chondrocyte differentiation in vitro and in vivo, which highly suggest that QDs can be applied to the long-term in vivo imaging diagnostics. Berry, et al. [49] reported that quantum dots functionalized with 

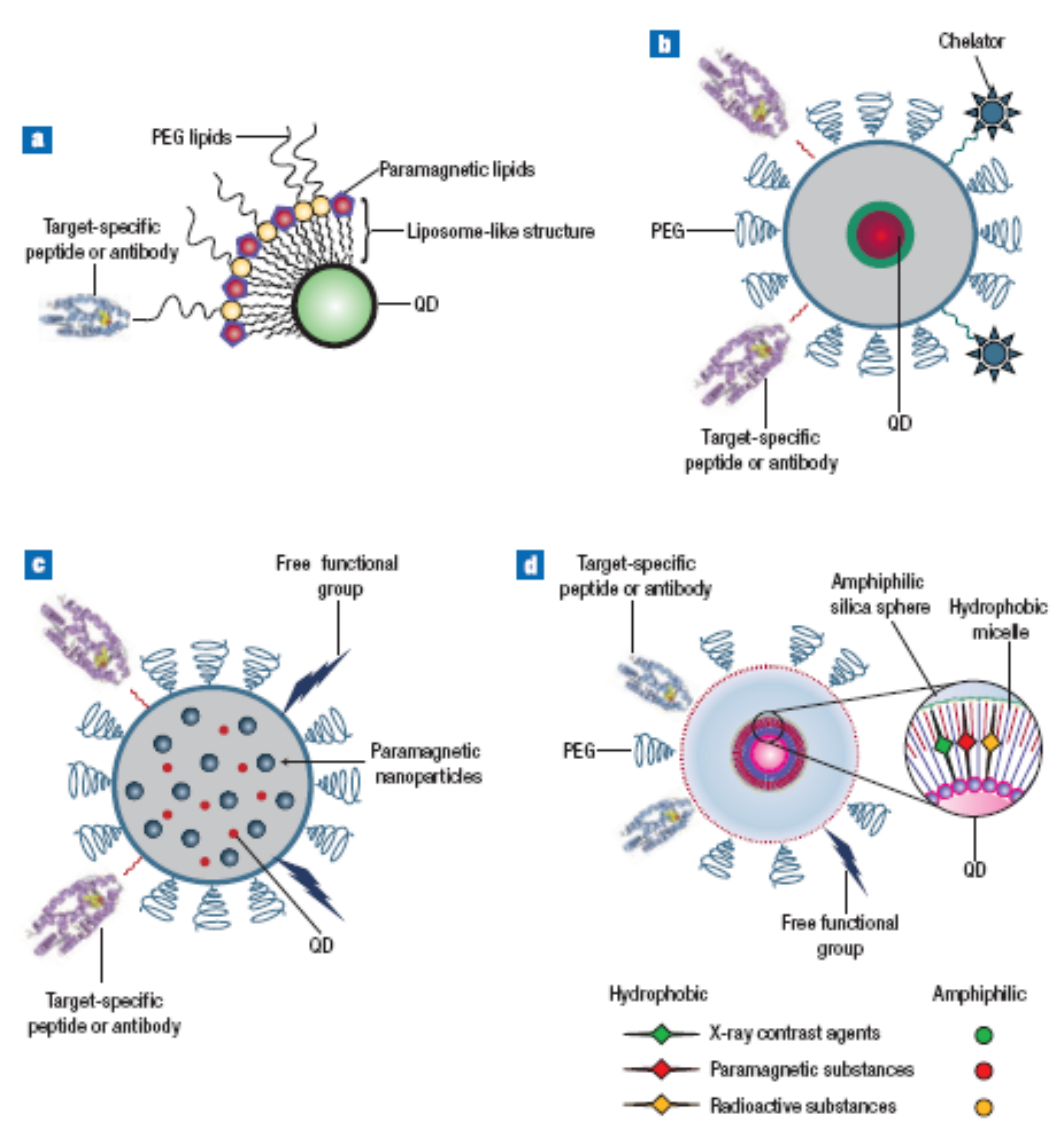

Figure 2. Various designs of multimodal QD probes. (a,b) Quantum dots having different molecules for targetspecific interaction, and, attached to the surface, paramagnetic lipids, and chelators for nuclear-spin labeling. (c) The silica sphere has QDs and paramagnetic nanoparticles inside and target-specific groups attached to the outside. (d) The structure of a multimodal QD probe, based on silica-shelled single-QD micelles [49].

can be isolated directly in vitro in magnetic fields. Another report supported that the QDs covered carbon nanotubes can be internalized into stem cells, and realized labelling stem cells [62].

Ruiz-Cabello, et al. [63] also investigated the stem cellular internalization of cationic and anionic perfluoro-15-crown-5-ether (PFCE) nanoparticles using cell culture plates with different surface coatings by F-19 MR. Results showed that the viability and proliferation of anionic and cationic PFCE-labeled neural stem cells (NSCs) did not differ from unlabeled cells. Cationic PFCE nanoparticles were superior to anionic particles for intracellular fluorination. After injecting PFCE-labeled NSCs into the striatum of mouse brain, cells were readily identified in vivo by MRI without changes in signal or viability over a 2week period after grafting. These results highly suggest that neural stem cells can be efficiently fluorinated with cationic PFCE nanoparticles and visualized in vivo over prolonged periods with an MR sensitivity of approximately 140 pmol of PFCE/cell.
Liu, et al. [64] reported that $100 \mathrm{~nm}$ carboxylated nanodiamond (ND) particles can be taken into stem cells by macropinocytosis and clathrin-mediated endocytosis pathways, and the cell growth ability was not altered by endocytic ND particles after long-term cell culture for 10 days in both A549 lung cancer cells and 3T3-L1 embryonic fibroblasts. Finally, the cell retained a single ND's cluster in cytoplasm after subcultured for several generations. Interestingly, ND's clusters were carried inside of cells but did not induce damages after long-term cell culture. These observations highly suggest that endocytic ND particles are non-cytotoxic in cell division and differentiation, which can be applied for the labeling and tracking of cancer and stem cells [65].

\subsection{Stem cell nanotechnology for gene delivery}

The rapid development of generating progenitor cells with in vivo reconstitution functions has accelerated biomedical applications of embryonic stem cells (ES) in the treatment of debilitating genetic, traumatic, and 

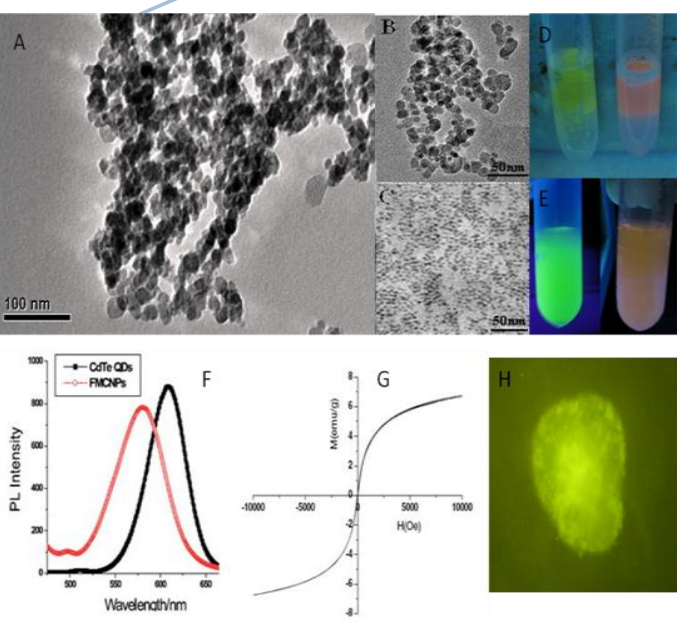

Figure 3. TEM images of (A) FMNPs (B) magnetic nanoparticles and (C) quantum dots (D) aggregated fluorescent magnetic nanoparticles under the magnetic field (E) prepared fluorescent magnetic nanoparticles with red or green color (F) PL spectra of CdTe QDs and FMNPs (G) Field-dependent magnetization curve of FMNPs at room temperature. $(\mathrm{H})$ Fluorescent microscope image of FMNPs inside murine ECC stem cells [62]

degenerative conditions [66]. Physical methods such as electroporation and nucleofection offer the advantage of high delivery efficiency but frequently cause severe damage to ES cells [67]. Viral vectors, including retro-, lenti-, and adenoviruses, can produce high-efficiency transfection, but their disadvantage of easy mutagenesis ignificantly decrease clinical applications [68]. Therefore, non-viral vectors such as polymeric nanoparticles and liposomes are currently recognized as the most promising nanotechnology and have the potential clinical applications $[69,70]$.

In our research, we report that No.5 generation of polyamidoamine dendrimer-functionalized fluorescent multi-walled carbon nanotubes(dMNTs) can enter into mouse embryonic stem cell line CCE efficiently [61]. While incubated dMNTs dose are more than $20 \mu \mathrm{g} / \mathrm{ml}$, they can cause CCE cells become smaller as the incubation time increases, and inhibit cell growth in dose- and time-dependent means. On the other hand, dMNTs less than $5 \mu \mathrm{g} / \mathrm{ml}$ dose can improve CCE differentiation. Dendrimers is a novel special class of organic molecules: they can take different functional groups through a series of chemical modifications, and their interior cavities can serve as storage areas for a lot of genes or drugs [71]. Dendrimers may be a good nonviral delivery vector because it has the advantages of simplicity of use, and ease of mass production compared with viral vectors that are inherently risky for clinical use. Polyamidoamine (PAMAM) dendrimer-modified magnetic nanoparticles can markedly enhance the delivery efficiency for antisense oligonucleotides [72-74]. The prepared dMNTs may be a highly efficient gene delivery system for ES cells. So they have potential applications in ES research. As shown in Figure.4, nanoparticles such as magnetic nanoparticles $[36,48]$ and quantum dots can enter into human stem cells. As shown in Figure.4 D,I, J and K, we observed that $\mathrm{SiO}_{2}$ wrapped CdTe nanoparticles can enter into murine CCE stem cells and can be clearly observed that quantum dots existed in the induceddifferentiated neurons, hematopoietic cells, and endothelia cells which did not exhibit strong cytotoxicity.

More recently, a molecular delivery system by using atomic force microscopy (AFM) and nanoneedle has been developed to transfer gene into living cells [7577]. Han SW et al described a low-invasive gene delivery method that uses an etched AFM tip or nanoneedle that can be inserted into a cell nucleus without causing cellular damage. The nanoneedle is $200 \mathrm{~nm}$ in diameter and $6 \mathrm{um}$ in length and is operated using an AFM system. The probabilities of insertion of the nanoneedle into human MSCs and human embryonic kidney cells were higher than those of typical microinjection capillaries. A plasmid containing the green fluorescent protein (GFP) gene was adsorbed on a poly-l-lysine-modified nanoneedle surface, which was then inserted into primary cultured single human MSCs. A highly efficient gene delivery of over $70 \%$ was achieved in human MSCs, which compared very favorably with other major nonviral gene delivery methods (lipofection $\sim 50 \%$, microinjection $\sim 10 \%$ ).

Green, et al. [78] reported that they successfully prepared the small (similar to $200 \mathrm{~nm}$ ), positively charged (similar to $10 \mathrm{mV}$ ) particles formed by the self assembly of cationic, hydrolytically degradable poly(beta-amino esters) and plasmid DNA. They also created an OCT4-driven GFP hES cell line to allow the rapid identification of nanoparticles that facilitate gene transfer while maintaining the hESC undifferentiated state. Using this cell system, they synthesized nanoparticles that have gene delivery efficacy that is up to 4 times higher than that of the leading commercially available transfection agent, Lipofectamine 2000.Importantly, these nanoparticles have minimal toxicity and do not adversely affect hESC colony morphology or cause nonspecific differentiation.

Soenen, et al. [79] prepared the magnetoliposomes, and used magnetoliposomes to immobilize enzymes, both water-soluble and hydrophobic ones, were successfully investigated their potential applications including MRI, hyperthermia cancer treatment and drug delivery. 

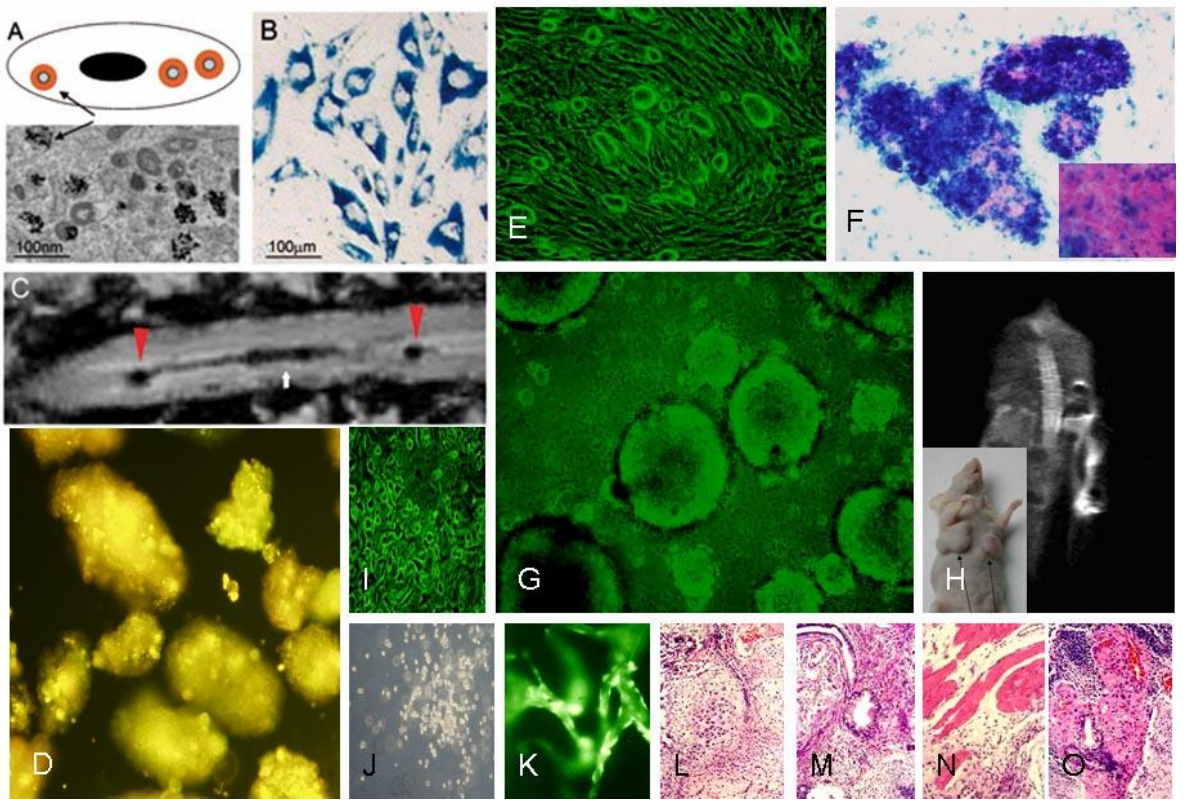

Figure 4. Drawing and transmission electron microscopy (TEM) image (A) and Prussian blue-positive cells (B) showing nanoparticles inside the cell (arrow). C: T2-weighted image of a rat spinal cord injected with nanoparticlelabeled MSCs. Arrowheads mark the injection sites, arrow the lesion populated with cells; implanted nanoparticles labeled mouse embryonic stem cells were labeled with superparamagnetic iron oxide nanoparticles (E-G). Cells were grafted intravenously. In vivo MRI was used to track their fate $(\mathrm{H})$. Prussian blue staining confirmed the presence of iron oxide nanoparticles inside the cells (F). After 4 weeks post-implantation, grafted cells migrated to the lesion site and formed teratomas composed of tissue of all 3 germ layers (L-M); In vitro differentiation of quantum dots labeling of human embryonic stem cells (D) into neurons (I), hematopoietic cells (J) and endothelia cells (K) [48].

\subsection{Effects of CNTs on proliferation and differentiation of stem cells}

Carbon nanotubes, because of unique mechanical, physical and chemical properties, have great potential applications in various fields including molecular electronics, medical chemistry and biomedical engineering [80-85]. Carbon nanotubes can be functionalized to achieve improved properties and functions such as biocompatibility and biomolecular recognition capabilities [86-87]. Protein-conjugated carbon nanotubes can across the cellular membrane and enter into cytoplasm and cell nucleus [88-89]. Carbon nanotubes which can be filled with DNA or peptide molecules have high potential in gene or peptide storage and delivery system in molecular therapy of diseases [90-91]. In our previous work, we investigated the effects of single walled carbon nanotubes (SWCNTs) on human embryonic kidney cell line HEK293 cells [92]. We observed that SWCNTs can inhibit HEK293 cell proliferation and decrease cell adhesive ability in a dose- and time-dependent manner. HEK293 cells exhibit active responses to SWCNTs such as secretion of some $20-30 \mathrm{kd}$ proteins to wrap SWCNTs, aggregation of cells attached by SWCNTs and formation of nodular structures. As shown in Figure.5, cell cycle analysis showed that $25 \mu \mathrm{g} / \mathrm{ml}$ SWCNTs in medium induced G1 arrest and cell apoptosis in HEK293 cells. Biochip analysis showed that SWCNTs can induce up-regulation expression of cell cycle-associated genes such as p16, bax, p57, hrk, $\operatorname{cdc} 42$ and $\operatorname{cdc} 37$, down-regulation the expression of cell cycle genes such as cdk2, cdk4, cdk6 and cyclin D3, and down-regulation expression of signal transduction-associated genes such as $\operatorname{mad} 2$, jak1, ttk, pcdha9 and erk. Western blot analysis showed that SWCNTs can induce down-regulation expression of adhesion-associated proteins such as laminin, fibronectin, cadherin, FAK and collagen IV. SWCNTs inhibit HEK293 cells growth by inducing cell apoptosis and decreasing cellular adhesion ability. It is also observed that SWCNTs stimulate human osteoblast cells and human fibroblast cells to appear many protuberance on the surface compared with the control, which is one kind of active protective reaction of stimulating cells. Regarding the mechanism of nanoparticles such as CNTs entering into cells, receptor-mediated endocytosis may be responsible for the phenomena. A theory model is also suggested that the optimal size of particles entering into cells is between $25 \mathrm{~nm}$ and $700 \mathrm{~nm}$ or so, too small nanoparticles are very difficult to enter into cells because of cellular surface tension force and adhesion. The further mechanism of effects of CNTs on human ES cells is being investigated from the following four scales such as molecular, cellular, animals and environment levels. 

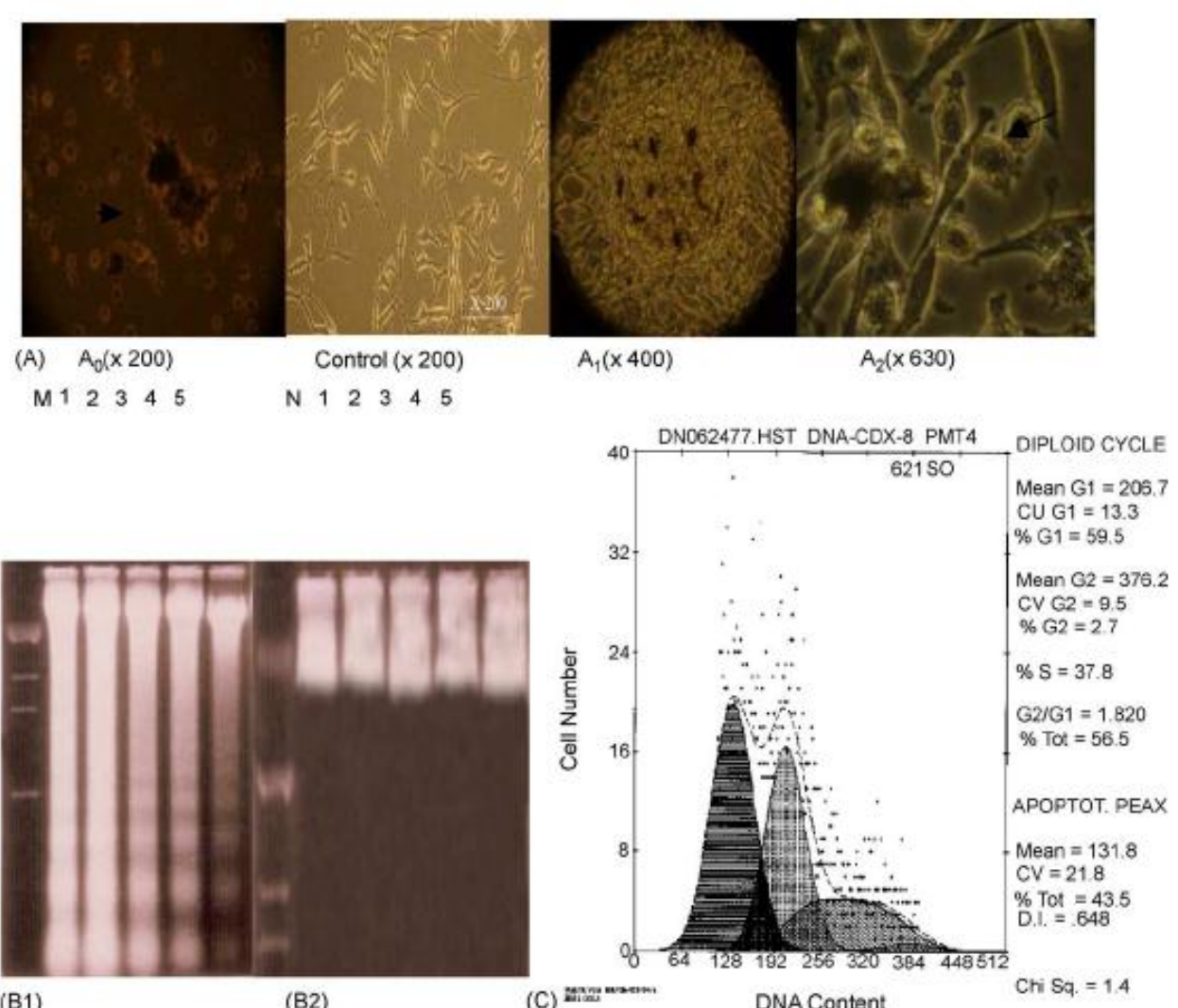

(B1)

(B2)

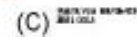

DNA Content

Figure 5. Apoptosis of HEK293 cells induced by SWCNTs. (A) morphological changes of HEK293 cells cultured with $25 \mu \mathrm{g} / \mathrm{ml}$ SWCNTs for three days; (A0): showing cells become round and floating with apoptotic characterizatics; control: showing normal morphological cells; A1: showing nodular structure composed of SWCNTs and apoptotic cells; A2: showing apoptotic cells attached by SWCNTs. B1: DNA electrophoresis of cells cultured with $25 \mu \mathrm{g} / \mathrm{ml} \mathrm{SWCNTs} \mathrm{for} \mathrm{1-} 5$ days, M: molecular Marker; no.1-5 denote the results of cells cultured for day 1- 5, respectively; B2: DNA electrophoresis results of control cells cultured for day 1-5; C: the cell cycle distribution of HEK293 cells cultured with $25 \mu \mathrm{g} / \mathrm{ml} \mathrm{SWCNTs} \mathrm{for} \mathrm{four} \mathrm{days,} \mathrm{the} \mathrm{percentage} \mathrm{of} \mathrm{sub-G1} \mathrm{cells}$ ( apoptosis cells) was 43.5\%[92].

Barron and his collaborators investigated effects of a range of different types of CNTs, including singlewalled nanotubes (SWCNTs), multi-walled nanotubes (MWCNTs) and functionalized CNTs on hMSCs, and revealed that at low concentrations of $\mathrm{COOH}-$ functionalized SWCNTs, the CNTs had no significant effect on cell viability or proliferation [93]. In addition, by fluorescently labeling the $\mathrm{COOH}$ functionalized SWCNTs; the CNTs were seen to migrate to a nuclear location within the cell after $24 \mathrm{~h}$ without adversely affecting the cellular ultrastructure. Moreover, the CNTs had no affect on adipogenesis, chondrogenesis or osteogenesis. So far CNTs have been considered to be one novel and emerging technology in gene or drug delivery, tissue engineering and regenerative medicine. At low concentrations, CNTs have minimal effect on MSCs viability and multipotency. Therefore, they have great potential to advance the field in a number of ways including: 1) Development of nanovehicles for delivering biomolecule-based cargos to MSCs; 2) Creation of novel biomedical applications for electroactive carbon nanotubes in combination with
MSCs. Since carbon nanotubes are electrically conductive, there is a huge potential for the manipulation of MSCs differentiation pathways to create electroactive cells such as those found in the heart. In particular, specific applications could result in novel MSCs based cell therapies for electroactive tissue repair; novel biomolecule delivery vehicle for manipulation of MSCs differentiation pathways and electroactive CNTs scaffolds for damaged electroactive tissues.

\subsection{Application of 3D nanostructures in stem cell tissue engineering}

The combination of stem cells with tissue engineering principles enables developing the stem cell-based therapeutic strategy for human diseases. Stem cell and progenitor cell directional differentiation is currently one hotspot, the differentiation of stem cells that conjugate $3 \mathrm{D}$ materials is considered as the most perspective tissue engineering. Up to date, various micro/nanofabrication technologies have been used to guide stem cells to develop into three- 
dimensional biodegradable scaffolds [94-95]. Nanostructured scaffolds are designed to trigger stem cells to become specific cell types compromising the tissues and organs in the body. Inside these scaffolds, cells deposit their own matrix and as the scaffold degrades, they form a 3D tissue structure that mimics the body's natural tissues. For example, Gelain et al reported that they had developed a 3-D cell culture system using a designer peptide nanofiber scaffold with mouse adult neural stem cells [96]. They synthesized 18 different peptides which directly incorporate various functional motifs to promote cell adhesion, differentiation and bone marrow homing activities. These functionalized peptides self-assemble into nanofiber scaffolds where cells can be fully embedded by the scaffold in 3-D dimension. Without addition of soluble growth factors and neurotrophic bone marrow homing motifs not only significantly enhanced survival of the neural stem cells, but also promoted differentiation towards cells expressing neuronal and glial markers.

As shown in Figure.6 and Figure.7, carbon nanotube patterns can be used to guide growth and alignment of mesenchymal stem cells (MSCs). The MSCs exhibited preferential growth on CNT patterns, and the cell culture results suggested that the CNT patterns did not have a harmful effect on the MSCs. The result clearly shows that CNT patterns have enormous potential as a new platform for basic research and applications using stem cells [97].

Stem cell differentiation is closely associated with their microenvironment. The regulation of stem cells depends largely on their interaction with a highly specialized microenvironment or "niches" [98].

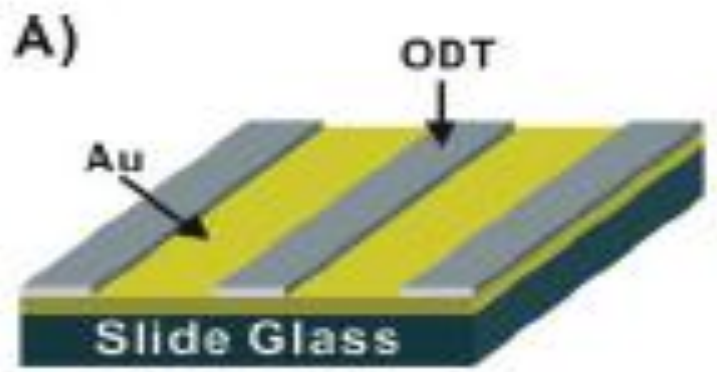

ODT Patterning on Au

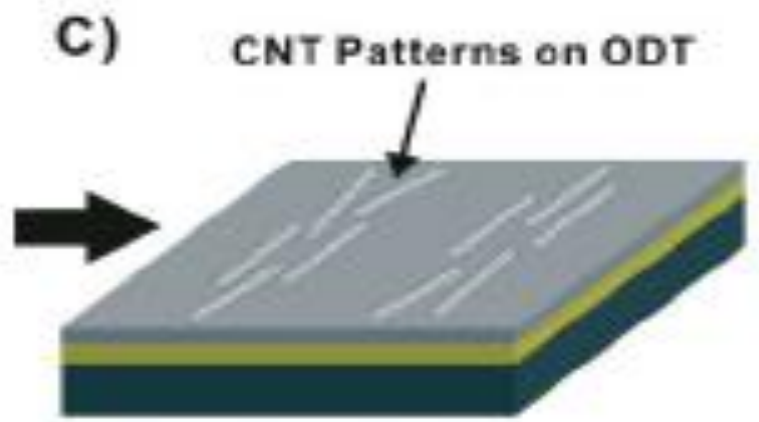

ODT Passivation
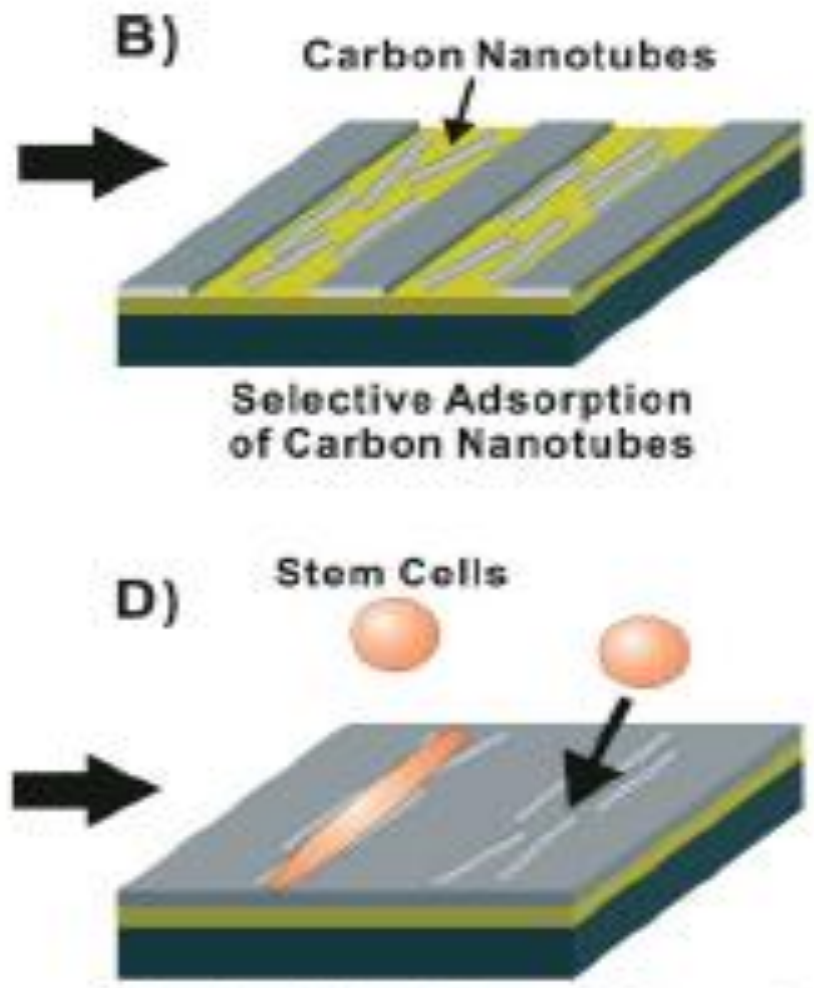

Selective Adhesion and Extension of Stem Cells onto CNT Patterns

factors, two of these scaffolds functionalized with

Figure 6. Schematic diagram depicting the directed growth of mesenchymal stem cells (MSCs) on large-scale carbon nanotube patterns. (A) Patterning of non-polar 1-octadecanethiol (ODT) SAM while leaving some bare Au area. (B) Selective adsorption and precision alignment of carbon nanotubes directly onto a bare Au surface. (C) Passivation of the exposed bare Au surface between the aligned carbon nanotubes with ODT. (D) Directed growth of MSCs onto the carbon nanotube patterns [97]. 


\section{A)}
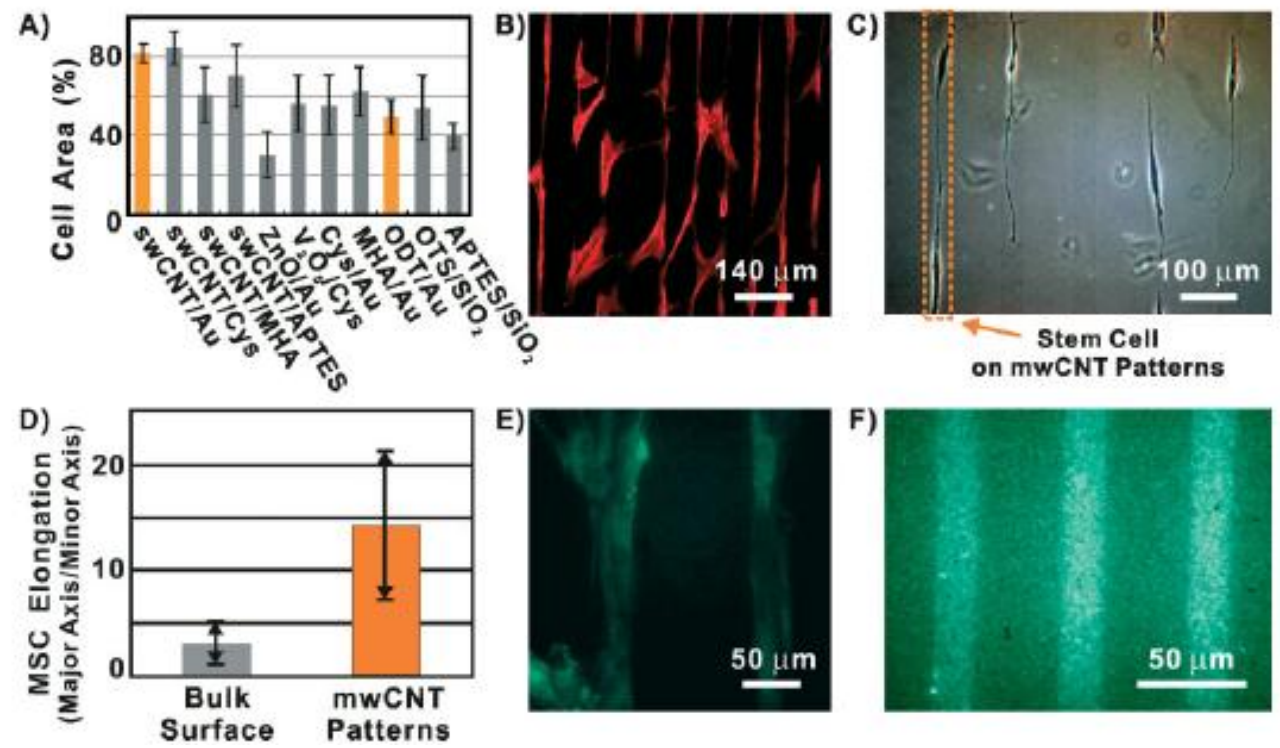

Figure 7. A) MSCs adhesion on various nanostructures and self-assembled monlayer (SAM) on $\mathrm{Au}$ or $\mathrm{SiO}_{2}$ surfaces. MSC spreading was characterized by measuring the cell area in actin filament fluorescence images. The surfaces studied are SWCNTs on Au (SWCNT/Au), SWCNTs on cystamine SAM on Au (SWCNT/Cys), SWCNTs on MHA SAM on Au (CNT/MHA), SWCNTs on APTES SAM on $\mathrm{SiO}_{2}(\mathrm{CNT} / \mathrm{APTES}), \mathrm{ZnO}$ nanowires on Au $(\mathrm{ZnO} / \mathrm{Au}), \mathrm{V}_{2} \mathrm{O}_{5}$ nanowires on cysteamine $\mathrm{SAM}$ on $\mathrm{Au}\left(\mathrm{V}_{2} \mathrm{O}_{5} /\right.$ Cys $)$, OTS SAM on $\mathrm{SiO}_{2}\left(\mathrm{OTS} / \mathrm{SiO}_{2}\right)$, and APTES $\mathrm{SAM}$ on $\mathrm{SiO}_{2}$ ( APTES/ $\mathrm{SiO}_{2}$ ). B) Fluorescence microscope image of actin filaments in MSCs adsorbed onto SWCNT patterns on Au surface. SWCNTs were adsorbed onto bare Au with ODT SAM as passivation layer. C) Optical microscope image of MSCs adhered onto mwCNTs/ ODT SAM patterns $(50 \mu \mathrm{m}$ wide mwCNT regions and $100 \mu \mathrm{m}$ wide ODT regions) with ODT passivation after $24 \mathrm{~h}$ of cell culture. The mwCNT regions appear as dark areas around the MSCs. D) Elongation of MSCs on bulk swCNT substrates or swCNT line patterns as in B). E) Fluorescence microscope image of vinculins represaenting focal adhesions of MSC adsorbed onto swCNT patterns on Au. F) Immunofluorescence image of the fibronectins adsorbed on the swCNT patterns on Au substrate [97].

Secreted factors, stem cell neighboring cell interactions, extracellular matrix $(\mathrm{ECM})$ and mechanical properties collectively make up the stem cell microenvironment. The niche secretes appropriate chemicals to direct the differentiation and development of stem cells. For example, Scadden's group has identified the elements of the microenvironment that control the behavior of mammalian stem cells [99]. Mineral components are important to stem cell localization; matrix components are important to constraint of stem cells; and bone-forming osteoblasts are also very important to the support and proliferation of stem cells, the calcium-sensing receptor, located on the surface of HSCs and other cells are critical for stem cells to find their niche.

A key challenge in stem cell microenvironment research is how to develop in vitro system that accurately imitates the in vivo microenvironment [100]. Nanotechnology can be utilized to create in vivo-like stem cell microenvironment to determine mechanisms underlying the conversion of an undifferentiated cells into different cell types [101]. A better solution is currently under investigation: growing the stem cells on a so-called "lab-on-a-chip" [102]. This is a silicon chip with nano reservoirs. The chip surface contains about a thousand reservoir cavities, with each reservoir only about 500 nanometers across. A reservoir holds a small amount of liquid chemicals similar to what the stem cells would be exposed to in the niche. Each reservoir is sealed with a lipid bilayer equivalent to a cell membrane. These reservoir bilayers also contain the same voltage-gated channels found in cells. A small charge of electricity can then be applied to any individual reservoir to open the channels allow the chemicals to spill out, delivering them to any particular stem cell at any specified time of development. The nano reservoir chip technology also allows the possibility of growing cells layer by layer, making compound tissues, which are otherwise difficult to produce.

Substrate topography influences a wide range of stem cell behaviors in a manner distinct from surface chemistry. One physical difference in the topography of divergent basement membranes is the size of pores and ridges. In vivo, cells never see flat surfaces: on the nanoscale, no basement membrane or extracellular matrix is flat. The great majority of features in the extracellular environment are in the submicron to nanoscale range, ensuring that an individual cell can be in contact with numerous topographic features [103105]. For example, Castano, et al focused on the thickness of polypyrrole films and their potential as a 
biocompatible material for rat MSCs [106]. Others have investigated the potential of electrospun porous scaffolds of randomly oriented $500 \mathrm{~nm}$ to $900 \mathrm{~nm}$ diameter nanofibers for cartilage repair [107-108]. Nanofibrous structures can favorably modulate osteoblast, osteoclast, and fibroblast activities toward implant and/or scaffold materials [109]. Nanofibrous matrices are introduced as scaffolds that may have a better structural resemblance to target tissues than their bulk counterparts, because major components in tissues are nanoscale structures and cells appear to attach and proliferate better on nanoscale structures than on bulk materials. So far there is a rapidly growing interest in synthesis of natural polymer based nanofibers because of their proven biocompatibility and resorbable biodegradation products. Advantageous attributes of natural polymers include hydrophilicity, nontoxicity, less immune reaction, as well as enhanced cell adhesion and proliferation. However, fabrication of natural polymer nanofibers by electrospinning is challenging. Chitosan and alginate, two abundant natural polymers, have been widely used in tissue engineering, but none had been fabricated into nanostructured matrices until in recent two years. Zhang's group reported that they successfully used Chitosan- and alginate- based nanofibrous matrices to mimic the ECM of articular cartilage that primarily consists of type II collagen and proteoglycans (glycosaminoglycan, GAG) [110]. A kind of nanopit template was etched with the special conglomeration surface and nanopits less than 100 nanometer in diameter. In the flat culture surface and nutrient medium of nanopit align ordered, the stem cell could not differentiate. But in the nutrient medium concurrent of ordered and unordered align naopit, the stem cell could grow to the calcify ossature cell. The stem cell could obtain the signal from the template. The surface of the transplanted tissue is the nanoengineering surface, it can induce the stem cell grow into the ossature. Obviously, surface character plays an important role in stem cell development and it is a relative simple way to control stem cell.

\subsection{Stem cell nanotechnology for treatment of} diseases in regenerative medicine

The human body is an intricate biochemicalmechanical system, with an exceedingly precise hierarchical organization in which all components work together in harmony across a wide range of dimensions. Many fundamental biological processes take place at surfaces and interfaces (e.g.cell-matrix interactions), and these occur on the nanoscale. For this reason, current health-related research is actively following a biomimetic approach in teaming how to create new biocompatible materials with nanostructured features. The ultimate aim is to reproduce and enhance the natural nanoscale elements present in the human body and to thereby develop new materials with improved biological activities. Stem cell nanotechnology has a potentially revolutionary impact on the basic understanding and therapeutic approaches for regenerative medicine. So far some great advances have made over several years.

\subsubsection{Stem cell nanotechnology for the treatment of neurodegenerative disorders and brain injuries}

Nanotechnology plays more and more important role in stem cell therapy. For example, Stupp, et al. [111-112] reported that paralyzed mouse which is lead by spinal cord injury recover walking function after injection the nanofibre which conjugating the laminin and nerve stem cells 6 weeks later. The neurite sprouting/guiding epitope combine the integrin which adjust cell differentiation could actuate signal and stimulate neuraxis extension. After 24 hours, nerve stem cells begin to differentiate on damage position and generate new neuron which inhibit colloid cell form cicatrix and help recovery nerve. The nanofibre was degraded after 8 weeks. The experimental mice suffer severe spinal cord injury similar to human extremely severe damage caused by traffic accident. The regenerate method has great potential application in disease therapy such as Parkinson disease, apoplexy, cardiopathy, diabetes and so on [113].
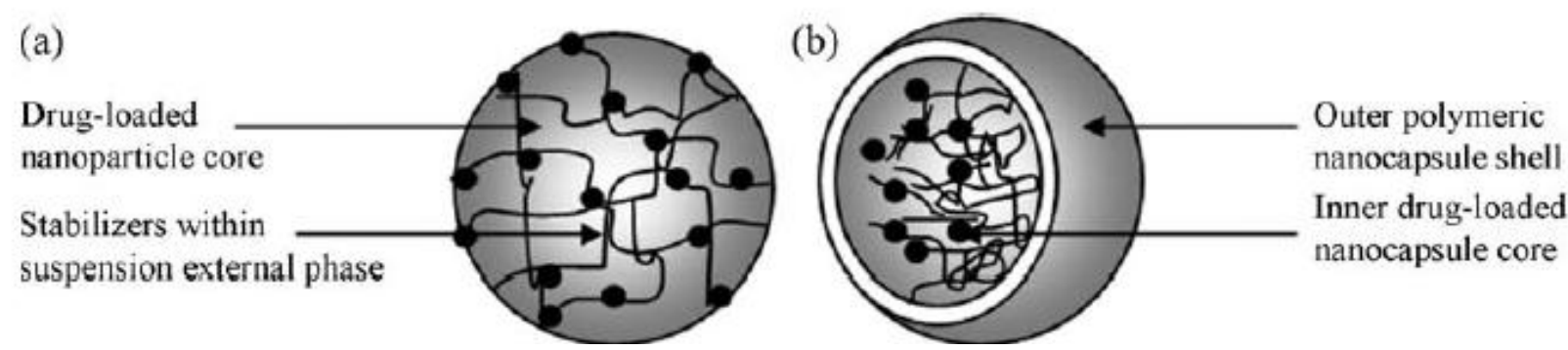

Figure 8. Illustrations of (a) functionalized and stable nanoparticles within a suspension and (b) the typical structure of a drug-loaded nanoparticle[114] 


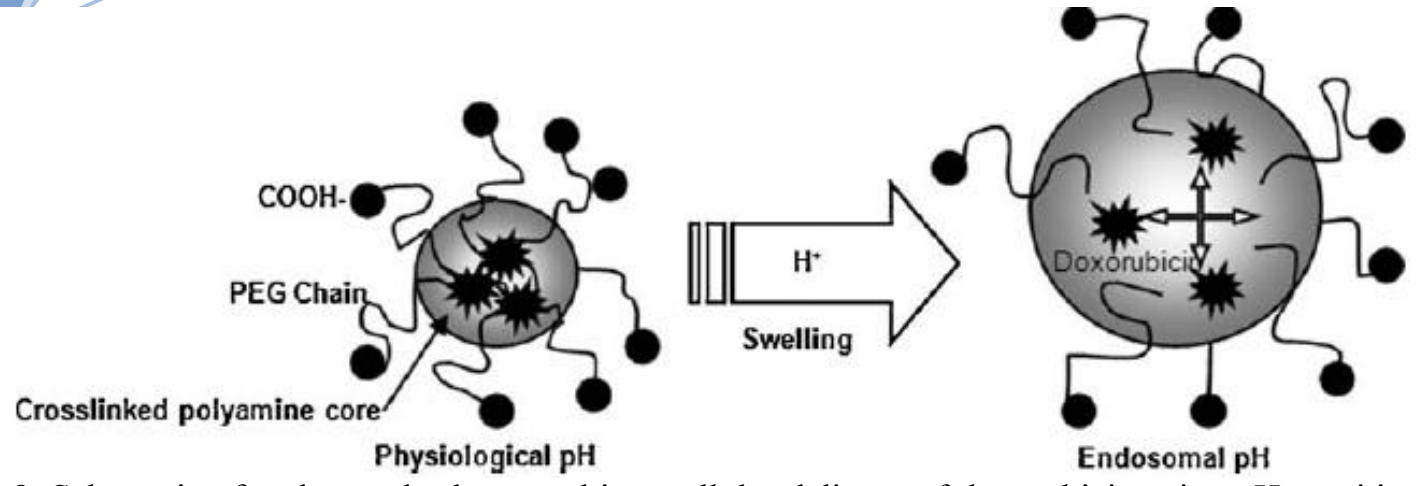

Figure 9. Schematic of endosomal release and intracellular delivery of doxorubicin using pH-sensitive PEGylated nanogels[114].

For the treatment of neurodegenerative disorders (NDs), conventional drug delivery systems do not provide adequate cyto-architecture restoration and connection patterns that are essential for functional recovery in NDs, due to limitations posed by the restrictive blood-brain barrier. Nanomaterials can get through the blood-brain barrier. Nanomaterials-based drug delivery systems, as shown in Figure. 8 and Figure.9, have been actively explored for the treatment of NDs. Especially, nanotechnology employs engineered materials or devices that interact with biological systems at a molecular level and could revolutionize the treatment of neurodegenerative disorders (NDs) by stimulating, responding to and interacting with target sites to induce physiological responses while minimizing side-effects. Nanomaterials and nanotechnology have been actively explored the application in the therapy of NDs, in particular Alzheimer's and Parkinson's diseases, and developed some innovative therapeutic modalities for the treatment of NDs [114].

For the treatment of neurodegenerative disorders (NDs), a lot of neural stem cells are needed. However, how to obtain enough neural stem cells is a challengeable task. A major limitation in the translation of stem cells technology to clinical applications is the lack of efficient control over their proliferation and differentiation. Some research results fully demonstrate that biomaterials with nanoscale surface topography can influence cell ignalin like adhesion, proliferation and differentiation. Therefore, the identification of biomaterials that support appropriate ES cell attachment, proliferation and differentiation into neural cells is an attractive strategy for therapy of NDs. For example, as shown in Figure.10, thin films of gold with surface topography of varying roughness were designed and fabricated by using a combination of microfabrication techniques, which can be used to direct differentiation of ES cell-derived neural precursors. As shown in Fig.11, the ES-derived neural precursors best adhered on gold and underwent the highest differentiation on gold films with root mean square surface roughness (R-q) of $21 \mathrm{~nm}(72+/-6 \%)$ after five days of culture in the absence of traditional soluble neurotrophic factors. Moreover, when cells were seeded on a combination of micro-scale grooves with nanoscale surface roughness, axonal outgrowth orientation was observed to be influenced by the grating axis [115]. Ultimately, substrate patterning may hold special utility in the design of neural prostheses because repair of neurological injuries requires directional guidance.

Stem cell nanotechnology has also been explored for the treatment of traumatic brain injury (TBI). As we know, traumatic brain injury is challenging and there is a need for neuroprotective therapies. One of the problems is to translation of promising animal experimental results into clinically successful therapies. The complexity of sequelae of TBI requires a multifaceted approach. In addition to the investigation of drugs for neuroprotective effect in TBI, new technologies based on cell/gene therapies, biomarkers and nanobiotechnology are being employed for the integration of neuroprotection with neuroregeneration and they have promising future [116].

For example, although transplantation of ES cellsderived neural progenitor cells has been demonstrated with success for either spinal cord injury repair in small animal model, but controlling of ES cell differentiation into complex, viable, higher ordered tissues are still challenging. Recent reports showed that the use of electrospun biodegradable polymers as scaffolds not only enhance the differentiation of mouse ES cells into neural lineages but also promote and guide the neurite outgrowth. A combination of electrospun fiber scaffolds and ES cells-derived neural progenitor cells could lead to the development of a better strategy for nerve injury repair [117].

Besides the data mentioned above, nanoscale biomaterials are also actively explored to apply to the treatment of nervous system disorders. For example, recently developed biomaterials can enable and augment the targeted delivery of drugs or therapeutic proteins to the brain, allowing cell or tissue transplants to be effectively delivered to the brain and help to 


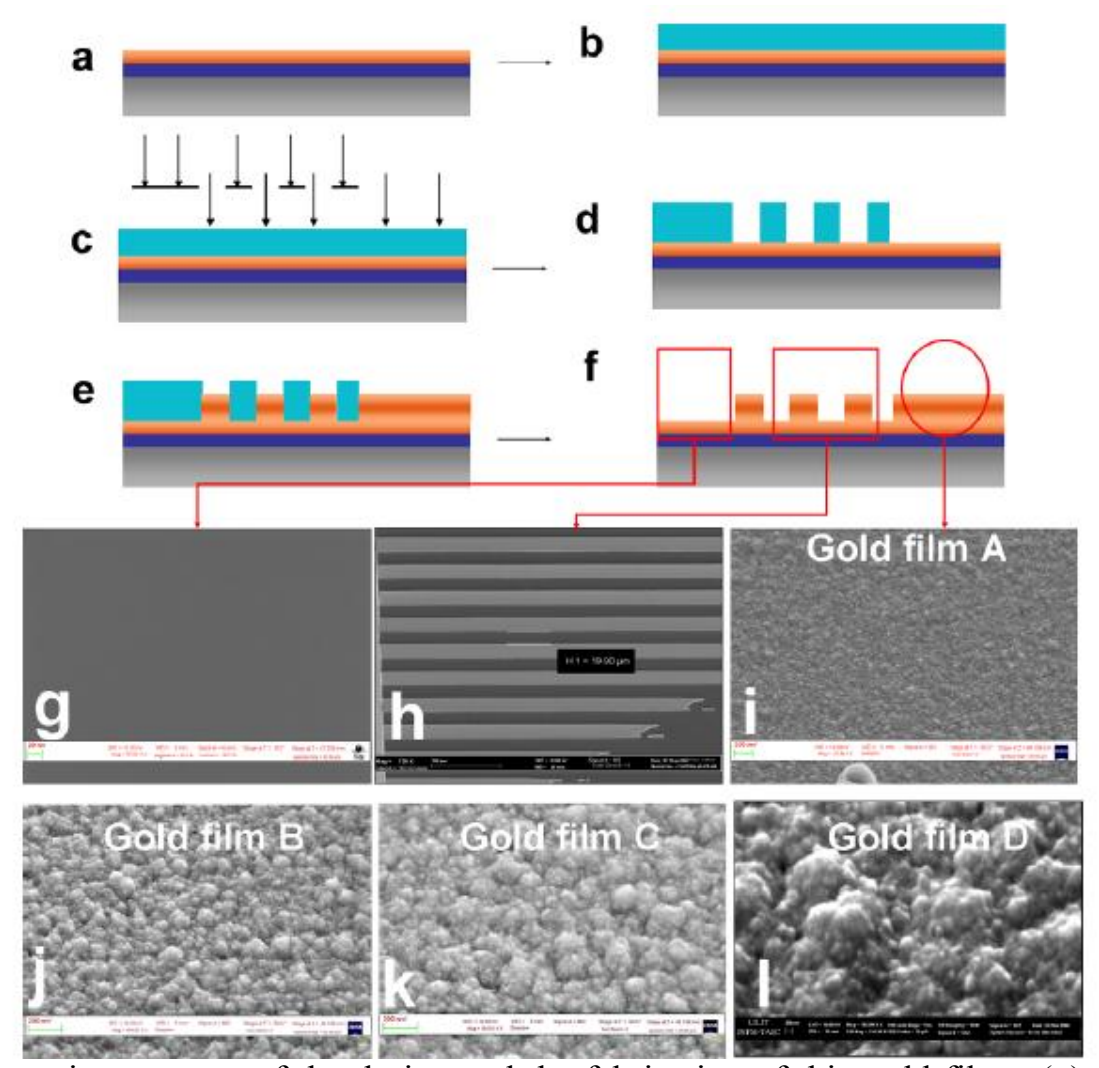

Figure 10. (a)-(f) Schematic summary of the design and the fabrication of thin gold films. (g)-(i) Representative SEM images of a gold film demonstrating three test surfaces realized on the chip; namely control (plarar gold),combined microgrooves with nano-roughness and nano-roughness respectively.(j) SEM images of gold films realized in this study qualitatively showing nano-agglomerations of increasing size.[115]

Day 3

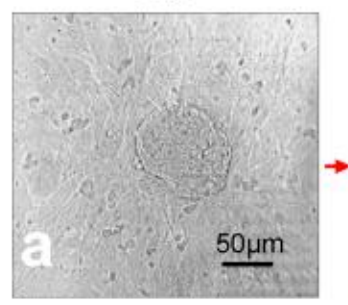

Planar gold (ctrl)
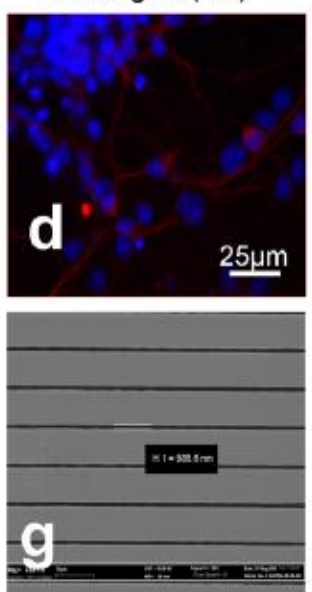

Day 6

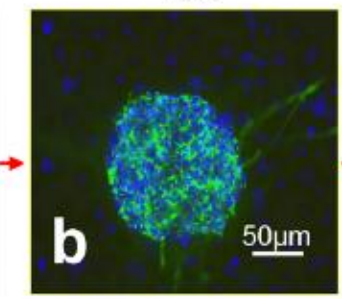

Gold film B (21 nm)
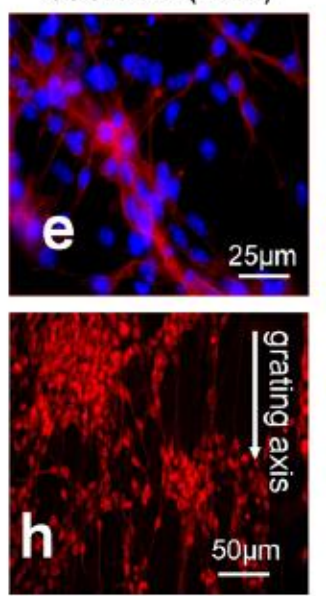

Nestin ${ }^{+}$precursors

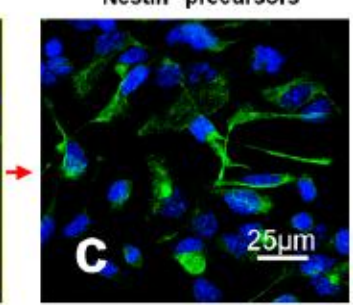

Gold film C (30nm)
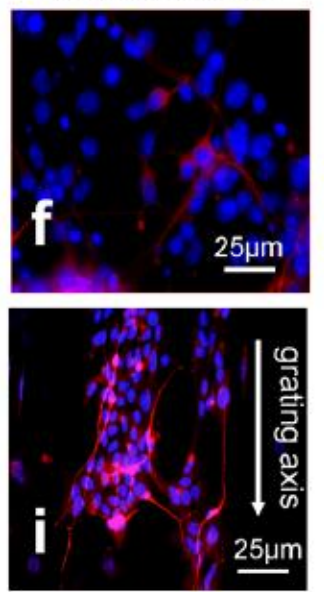

Figure 11. (a)-(c) Representative micrograph of the induction stages of the mES neural differentiation protocol [green nestin and blue DAPI stain for nuclear DNA]. (d)-(f), differentiation of neural precursor into post-mitotic TUJI-positive neurons(red) as a function of surface topography.(g) Representative SEM image of gold film with microscale grating on which axonal growth was orientated to the grating axis(h) and (i) [115] 
rebuild damaged circuits. Similarly, biomaterials are being used to promote regeneration and to repair damaged neuronal pathways in combination with stem cell therapies. Many of these approaches are gaining momentum because nanotechnology allows greater control over material-cell interactions that induce specific developmental processes and cellular responses including differentiation, migration and outgrowth [118].

Nitric oxide (NO) has been shown to inhibit neointimal hyperplasia after arterial interventions in several animal models. NO-based therapies have great potential in clinical application. Combining nanofiber delivery vehicles with $\mathrm{NO}$ chemistry can create a novel, more potent NO-releasing therapy that can be used clinically. Primary experiment showed that the spontaneously self-assembling NO-releasing nanofiber gels can be used to prevent neointimal hyperplasia [119-120].

\subsubsection{Stem cell nanotechnology for cartilage and bone tissue engineering}

Cartilage and bone tissue engineering has been widely investigated but is still hampered by cell differentiation and transplant integration issues within the constructs. Scaffolds represent the pivotal structure of the engineered tissue and establish an environment for neo-extracellular matrix synthesis. They can be associated to signals to modulate cell activity. The hydroxyapatite (HA) has been used for the cartilage repair, the membranes of electrospun fibers of poly-1lactic acid (PLLA) loaded with nanoparticles of HA were designed and fabricated for the putative chondrogenic differentiation of human mesenchymal stem cells (hMSCs).Results showed that the hMSCs were seeded on PLLA/HA and bare PLLA membranes and cultured in basal medium, using chondrogenic differentiation medium as a positive control. After 14 days of culture, SOX-9 positive cells could be detected in the PLLA/HA group. Cartilage specific proteoglycan immunostain confirmed the presence of neoextracellular-matrix production. Co-expression of CD29, a typical surface marker of MSCs and SOX-9, suggested different degrees in the differentiation process. We developed a hydroxyapatite functionalized scaffold with the aim to recapitulate the native histoarchitecture and the molecular signaling of osteochondral tissue to facilitate cell differentiation toward chondrocyte. PLLA/HA nanocomposites induced differentiation of hMSCs in a chondrocyte-like phenotype with generation of a proteoglycan based matrix. This nanocomposite could be an amenable alternative scaffold for cartilage tissue engineering using hMSCs [121].

Due to the fast progress being made in tissue regeneration therapy, biomaterials which used as scaffolds are expected to play an important role in future clinical application. Aoki, et al. reported a thin 3D carbon-fiber web as a scaffold for bone-tissue regeneration. The $3 \mathrm{D}$ web is consisted of high-purify carbon fibers in a nanoscale structure, as shown in Figure.12.When the thin carbon-fiber web (TCFW) and recombinant human bone morphogenetic protein 2(rhBMP-2) composite is implanted in the murine back muscle, new ectopic bone is formed, and the values of the bone mineral content and bone mineral density are significantly higher than those obtained with a collagen sheet, as shown in Fig.13, the rhBMP-2/TCFW composite repairs a critical-size bone defect within a short time period. These results suggest that the TCFW functions as an effective scaffold material and will play an important role in tissue regeneration in the near future [122].

Topographical modification of an orthopaedic implant may be a viable method to guide tissue integration and has been shown in vitro to dramatically influence osteogenesis, inhibit bone resorption and regulate integrin mediated cell adhesion. Integrins function as force dependant mechanotransducers, acting via the actin cytoskeleton to translate tension applied at the tissue level to change cellular function via intricate signaling pathways. In particular the ERK/MAPK signaling cascade is a known regulator of osteospecific differentiation and function. Biggs, et al. reported the effects of nanoscale pits and grooves on focal adhesion formation in human osteoblasts (HOBs) and the ERK/MAPK ignaling pathway in mesenchymal populations. Nanopit arrays disrupted adhesion formation and cellular spreading in HOBs and impaired osteospecific differentiation in skeletal stem cells. HOBs cultured on $10 \mathrm{~nm}$ wide groove/ridge arrays formed significantly less focal adhesions than cells cultured on planar substrates and displayed negligible differentiation along the osteospecific lineage, undergoing up-regulation in the expression of adipospecific genes. Conversely, osteospecific function was correlated to increased integrin mediated adhesion formation and cellular spreading as noted in HOBS cultured on 100 wide groove arrays. The osteospecific differentiation and function was linked to focal adhesion growth and FAK mediated activation of the ERK/MAPK signaling pathway in mesenchymal populations [123].

Topographical modification and surface microroughness of these devices regulate cellular adhesion, a process fundamental in the initiation of osteoinduction and osteogenesis. In particular, nanotedulology has allowed the development of nanoscale substrates for the investigation into cell-nanofeature interactions. Human osteoblasts (HOBS) were cultured on ordered nanoscale pits and random nano "craters" and "islands". Nanotopographies affected the formation of adhesions 
on experimental substrates. Adhesion formation was prominent on planar control substrates and reduced on nanocrater and nanoisland topographies; nanopits, however, were shown to inhibit directly the formation of large adhesions. STRO-1+ progenitor cells cultured on experimental substrates revealed significant changes in genetic expression, which implicates nanotopographical modification can be used as a significant modulator of osteoblast adhesion and cellular function in mesenchymal populations [124].

The primary human osteoblasts (HOBs) were cultured on ordered nanoscale groove/ridge arrays fabricated by photolithography. Grooves were $330 \mathrm{~nm}$ deep and 10, 25 or $100 \mathrm{~nm}$ in width. Nanotopographies significantly affected the formation of focal complexes (FXs), focal adhesions (Fas) and supermature adhesions (SMAs). Planar control substrates induced widespread adhesion formation; $100 \mathrm{~mm}$ wide groove/ridge arrays did not significantly affect adhesion formation yet induced upregulation of genes involved in skeletal development and increased osteospecific function; $25 \mathrm{~nm}$ wide groove/ridge arrays were associated with a reduction in SMA and an increase in FX formation; and $10 \mathrm{~nm}$ wide groove/ridge arrays significantly reduced osteoblast adhesion and induced an interplay of up- and downregulation of gene expression, which highly indicates that groove/ridge topographies are important modulators of both cellular adhesion and osteospecific function and, critically, that groove/ridge width is important in determining cellular response [125].

Biggs, et al. reported that nanohybrid scaffolds mimicking extracellular matrix are promising experimental models to study stem cell behavior in terms of adhesion and proliferation. Ca-deficient hydroxyapatite nanocrystals (d-Hap) were synthesized by precipitation. Fibrous PCL/d-HAp nanohybrids were obtained by electrospinning, d-HAp content ranging between 2 and 55 wt \% Electrospun mats showed a non-woven architecture, average fiber size was $1.5+/-0.5 \mathrm{~nm}$, porosity $80-90 \%$, and specific surface area was $16 \mathrm{~m}^{2} / \mathrm{g}$. Up to 6.4 wt $\%$ d-HAp content, the nanohybrids displayed comparable microstructural, mechanical and dynamo-mechanical properties. Murine ES cells response to neat PCL and to nanohybrid PCL/d-HAp (6.4 wt \%) mats was evaluated by analyzing morphological, metabolic and functional markers. Cells growing on either scaffold proliferated and maintained pluripotency markers at essentially the same rate as cells growing on standard tissue culture plates with no detectable signs of cytotoxicity, despite a lower cell adhesion at the beginning of culture. These results indicate that electrospun PCL scaffolds may provide adequate supports for murine ES cell proliferation in a pluripotent state, and that the presence of d-HAp within the mat does not interfere with their growth [126].
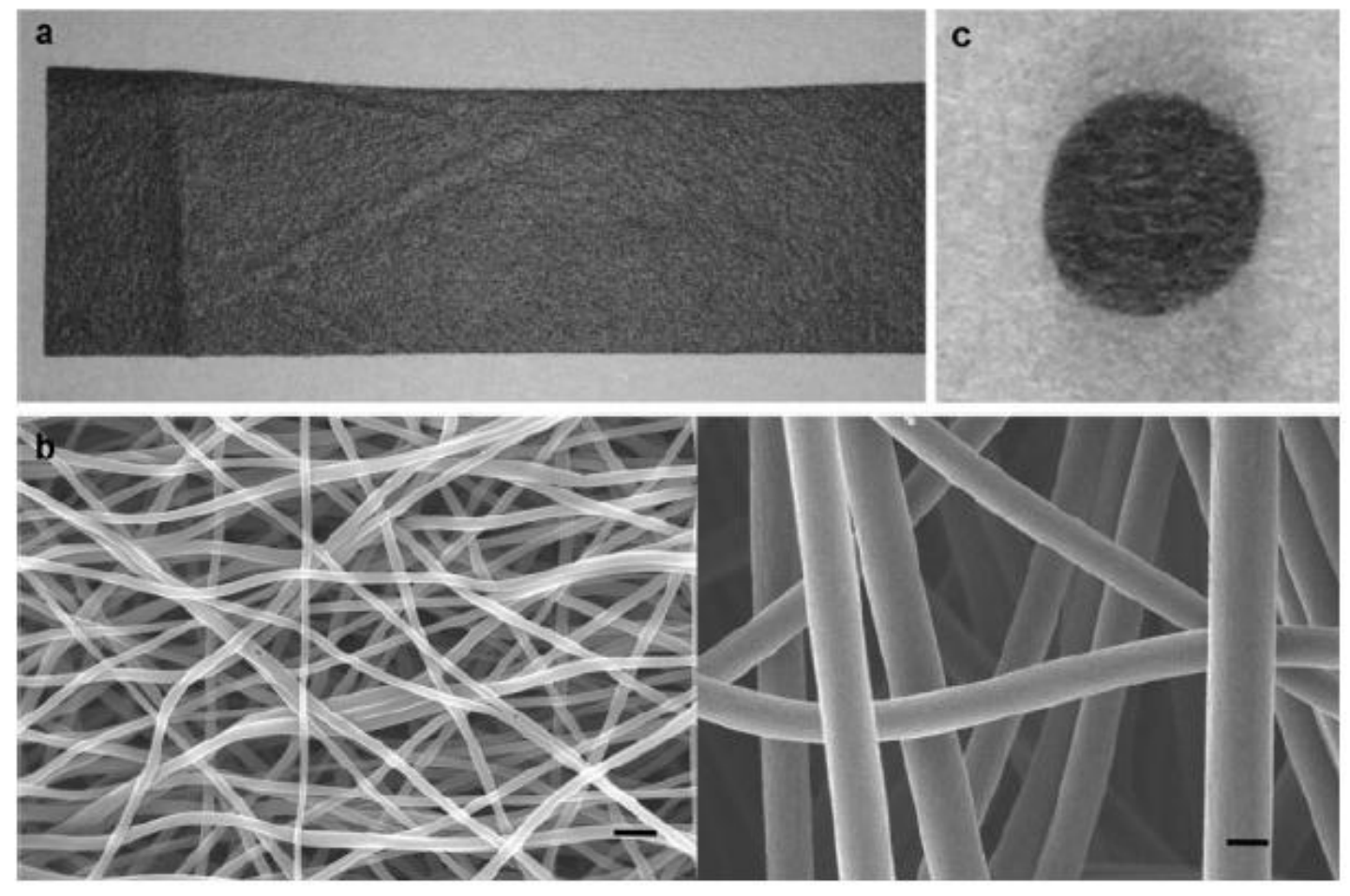

Figure 12. Images of the TCFW a) macroscopic view of the TCFW knitted into a soft black sheet. B) SEM images of TCFWs with diameters of $250 \mathrm{~nm}$ (left) and $1000 \mathrm{~nm}$ (right). Fine fibers built up to a nano- to microscale pore structure. C) Macroscopic view of the 1000-nm- diameter TCFW clipped into circular implants (5mm in diameter). Scale bar in (b): $1 \mu \mathrm{m}[122]$ 

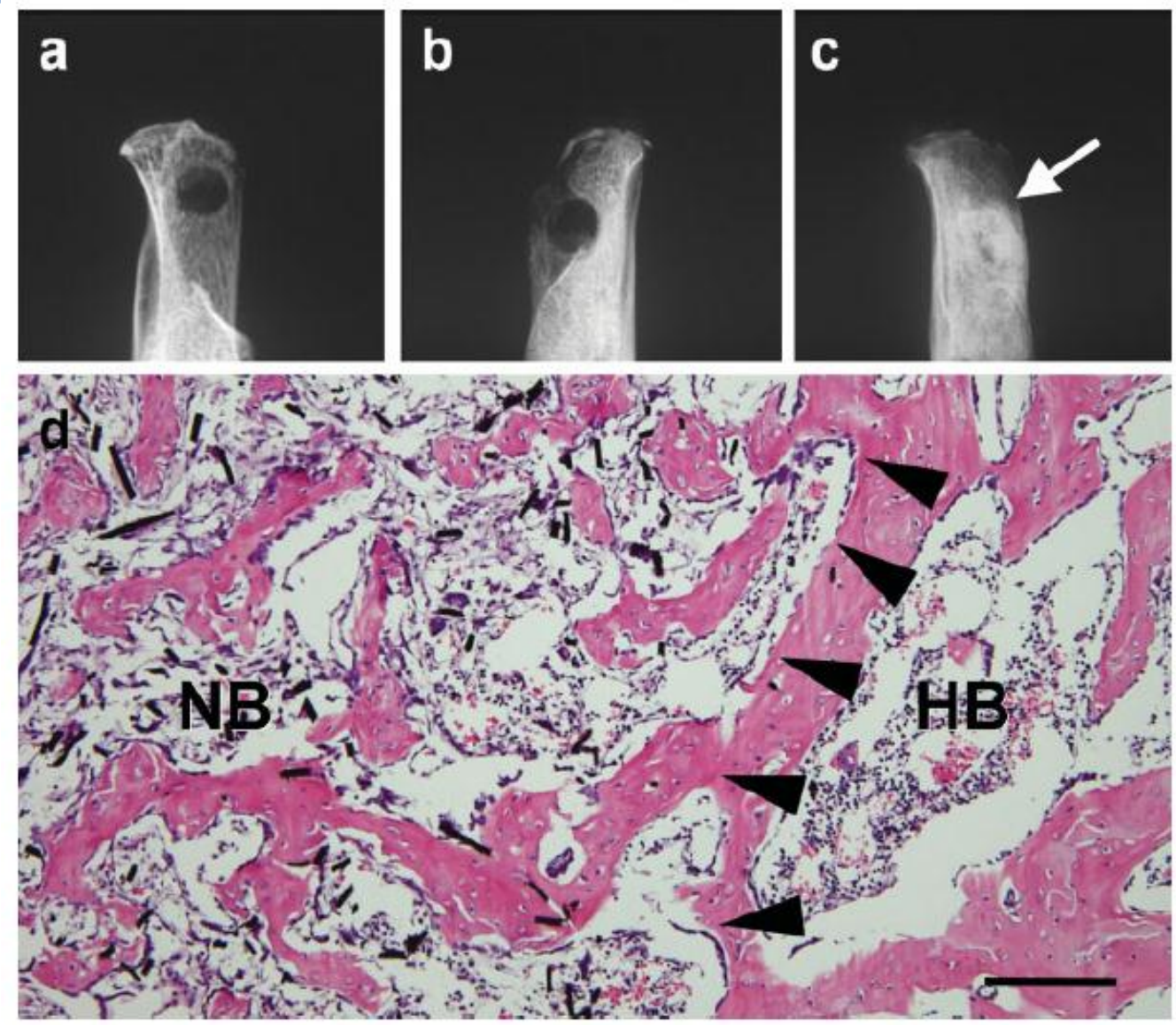

Figure 13. Repair of critical -sized bone defects in the rat ilia by the rhBMP-2/TCFW composite implants. A-c) Soft X-ray photographs of the regions of rat ileum bone defects at 4 weeks after the operation. Bone defects without implantation were not repaired and were of a critical size with a diameter of $4 \mathrm{~mm}$ (a). Very slight bones were formed in the defect containing the TCFW without rhBMP-2 (b). The bone defects were completely restored by the TCFW with $5 \mu \mathrm{g}$ of rhBMP-2(arrow) (c. d) Histology of the regions of rat ileum bone defects obtained 4 weeks after implantation in the TCFW with $5 \mu \mathrm{g}$ of rhBMP-2 group. A section of the host-defect interface (arrow heads) shows that new bone (NB) with hematopoietic marrow and bony trabeculae was formed adjacent to the host bone (HB). Scale bar: $50 \mu \mathrm{m}[122]$

\subsubsection{Stem cell nanotechnology for tissue engineering Scaffolds}

Embryonic stem cells represent a potentially unlimited cell source for tissue engineering applications. However, in order to be used for such applications, embryonic stem cells differentiation must be controlled to the desired lineages. Smith, et al. reported the effects of nanofibrous architecture and biochemical cues on the osteogenic differentiation of embryonic stem cells compared to the more traditional architecture without the nanofibrous features in two dimensions (thin matrix or flat films) and three dimensions (scaffolds) in vitro. After three weeks of culture the nanofibrous thin matrices were capable of supporting mRNA expression of osteogenic differentiation markers in embryonic stem cells without osteogenic supplements, while solid films required osteogenic supplements and growth factors to achieve mRNA expression of osteogenic differentiation markers. Nanofibrous scaffolds substantially enhanced mRNA expression of osteogenic differentiation markers compared to solid-walled scaffolds, nanofibrous thin matrices or solid films. After 4 weeks of culture, nanofibrous scaffolds were found to contain 3 times more calcium and stronger osteocalcin stain throughout the scaffolds than the solid-walled scaffolds. Overall, the nanofibrous architecture enhances the osteogenic differentiation and mineralization of embryonic stem cells compared to the solid-walled architecture in both two and three-dimensional cultures [127].

The human body is a complicated biochemicalmechanical system, with an exceedingly precise hierarchical organization which all components work together in harmony across a wide range of dimensions. Many fundamental biological processes take place at surfaces and interfaces, and these often occur on the nanoscale. So far the major techniques have been adopted to yield novel nanostructured versions of 
familiar biomaterials, focusing particularly on metals, which can beneficially guide biological processes, exerting influence on cellular behavior [128]. For example, Tambralli, et al. reported the development of a hybrid, nanostructured, extracellular matrix (ECM) mimicking scaffold by a combination of nanofibrous electrospun poly (epsiv-caprolactone) (ePCL) nanofibers and self-assembled peptide amphiphile (PA) nanofibers. The PAs have ECM mimicking characteristics including a cell adhesive ligand (RGDS) and matrix metalloproteinase-2(MMP-2) mediated degradable sites. PA self-assembly into nanofibers (diameters of 8-10 $\mathrm{nm}$ ) using a solvent evaporation method. This evaporation method was then used to successfully coat PAs onto ePCL nanofibers (diameters of 300-400 nm), to develop hybrid, bioactive scaffolds. The PA coatings did not interfere with the porous ePCL nanofiber network. Human mesenchymal stem cells (hMSCs) were seeded onto the hybrid scaffolds to evaluate their bioactivity. Significantly greater attachment and spreading of hMSCs were observed on ePCL nanofibers coated with PA-RGDS as compared to ePCL nanofibers coated with PA-S (no cell adhesive ligand) and uncoated ePCL nanofibers. Overall, this novel strategy presents a new solution to overcome the current bioactivity challenges of electrospun scaffolds and combines the unique characteristics of ePCL nanofibers and self-assembled PA nanofibers to provide an ECM mimicking environment [129].

A fast electrochemical anodization treatment, applying different anodic currents, was used to produce a nano/submicron-scale network oxide layer on $\mathrm{Ti}$ metal surface for biomedical implant application. Results showed that a nano/submicron-scale $\mathrm{TiO}_{2}$ network layer with a lateral pore size of 20-160 nm could be rapidly produced on $\mathrm{Ti}$ surface through electrochemical anodization treatment. Increasing the applied anodic current led to an increase in pore size of $\mathrm{TiO}_{2}$ network. The nano/submicron-scale $\mathrm{TiO}_{2}$ network layer significantly enhanced the whole blood coagulation and hBMSCs adhesion on Ti surface [130].

Silver nanoparticles were prepared by the polyol process, i.e. by the reduction of silver nitrate with ethylene glycol in the presence of polyvinylpyrrolidone PVP. Thereby, the silver nanoparticles were colloidally stabilized by the polymer. The synthesis of nanoparticles of different size and shape (cubes, rods and spheres) was possible by changing the reaction conditions such as reagent ratio and temperature. The biological activity of spherical PVP-coated silver nanoparticles (about 100nm diameter) was tested on human mesenchymal stem cells (hMSC) in comparison with equivalent amounts of silver ions (silver acetate). hMSC were treated with silver concentrations in the range of $50 \mathrm{ng} / \mathrm{mL}$ to $50 \mathrm{ng} / \mathrm{mL}$ for 7 days under cell culture conditions. Cytotoxic cell reactions occurred at $>=2.5 \mathrm{ng} / \mathrm{mL}$ for nanoparticles and $>=1 \mathrm{ng} / \mathrm{mL}$ for silver acetate, indicating a critical role of the silver ions for toxic reactions [131].

A computer-controllable scaffold structures were made by a layer manufacturing process (LMP) with addition of nano- or micro-sized particles. By using the LMP, a new nano-sized hydroxyapatite/poly(epsiloncaprolactone) composite (n-HPC) scaffold and a microsized hydroxyapatite/poly(epsilon-caprolactone) composite (m-HPC) scaffold were made for bone tissue engineering applications. The scaffold macropores were well interconnected, with a porosity of $73 \%$ and a pore size of $500 \mathrm{~mm}$. The compressive modulus of the n-HPC and m-HPC scaffolds was 6.76 and $3.18 \mathrm{MPa}$ respectively. Both n-HPC and m-HPC exhibited good in vitro biocompatibility. Attachment and proliferation of mesenchymal stem cells were better on the n-HPC than on the m-HPC scaffold. Moreover, significantly higher alkaline phosphatase activity and calcium content were observed on the n-HPC than on the mHPC scaffold. In an animal study, the LMP scaffolds enhanced bone formation, owing to their wellinterconnected pores. Radiological and histological examinations confirmed that the new bony tissue had grown easily into the entire n-HPC scaffold fabricated by LMP. We suggest that the well-interconnected pores in the LMP scaffolds might encourage cell attachment, proliferation, and migration to stimulate cell functions, thus enhancing bone formation in the LMP scaffolds [132].

\section{Bio-safety of stem cell nanotechnology during embryonic development}

With the rapid development of nanomaterials and nanotechnology, bio-safety of nanomaterials and nanotechnology has caused many governments' concern. Up to date, the effects of nanomaterials on environment and healthcare have been being actively investigated. However, few reports are closely associated with the area of developmental toxicity. How to clarify the mechanism of effects of nanomaterials and nanotechnology on the embryonic development is a big challengeable problem.

For example, Park, et al. reported that when mouse embryonic stem cells were exposed to silica nanoparticles at concentrations ranging from 1 to 100 $\mathrm{ng} / \mathrm{ml}$, the embryonic stem cells test showed a concentration dependent inhibition of differentiation of stem cells into contracting cardiomyocytes by two silica nanoparticles of primary size 10 (TEM 11) and 30 (TEM 34) nm while two other particles of primary size 80 (TEM 34) and 400 (TEM 248) nm had no effect up to the highest concentration tested. Inhibition of differentiation of stem cells occurred below cytotoxic concentrations, indicating a specific effect of the particles on the differentiation of the embryonic stem 
cells. The impaired differentiation of stem cells by such widely used particles warrants further investigation into the potential of these nanoparticles to migrate into the uterus, placenta and embryo and their possible effects on embryogenesis [133].

Deng, et al. reported the neurotoxicity of different sized zinc oxide $(\mathrm{ZnO})$ nanoparticles in mouse neural stem cells (NSCs). A cell viability assay indicatedthat $\mathrm{ZnO}$ nanoparticles manifested dose-dependent, but no size-dependent toxic effects on NSCs. Further test showed that the $\mathrm{ZnO}$ nanoparticle toxicity come from the dissolved $\mathrm{Zn}^{2+}$ in the culture medium or inside cells, which highlight the need for caution during the use and disposal of $\mathrm{ZnO}$ manufactured nanomaterials to prevent the unintended environmental and health impacts [134].

In recent years, the genotoxicology (the study of genetic aberrations following exposure to test agents) of nanomaterials is reported. For example, DNA damage may initiate and promote carcinogenesis, or impact fertility. The metal nanoparticles such as metaloxide nanoparticles, quantum dots, fullerenes, and fibrous nanomaterials, can damage or interact with DNA, for example, to cause genotoxic responses, such as chromosomal fragmentation, DNA strand breakages, point mutations, oxidative DNA adducts and alterations in gene expression profiles. However, there are clear inconsistencies in the literature and it is difficult to draw conclusions on the physico-chemical features of nanomaterials that promote genotoxicity [135].

Conversely, some reports clearly showed that the surface functionalized nanomaterials own good biocompatibility and advantageous bioactivity. For example, superparamagnetic iron oxide (SPIO) nanoparticles are very useful in cell imaging. However, biosafety concerns associated with their use, especially on therapeutic stem cells, have arisen. Huang, et al. reported that Ferucarbotran, an ionic SPIO, was not toxic to human mesenchymal stem cells (hMSCs) under the conditions of experiments but instead increased cell growth. Ferucarbotran-promoted cell growth is due to its ability to diminish intracellular $\mathrm{H}_{2} \mathrm{O}_{2}$ through intrinsic peroxidase-like activity. Also, Ferucarbotran can accelerate cell cycle progression, which may be mediated by the free iron (Fe) released from lysosomal degradation and involves the alteration of $\mathrm{Fe}$ on the expression of the protein regulators of the cell cycle [136].

Vaijayanthimala, et al. reported the biocompatibility and endocytosis mechanism of fluorescent nanodiamonds (FNDs) in cancer cells (HeLa) and preadipocytes (3T3-L1). Results showed that the mechanism of the FND uptake in both cells is by energy-dependent clathrin-mediated endocytosis. In addition, the surface charge of FND influences its cellular uptake, as the uptake of poly-L-lysine-coated FNDs is better than that of oxidative-acid-purified
FNDs at the same concentration in regular medium with or without serum. The proliferative potential of FND-treated and untreated cells does not exhibit any significant differences when measured at bulk cultures, and more stringently at clonal cell density. Further biocompatibility studies indicate that the in vitro differentiation of 3T3-L1 pre-adipocytes and 489-2 osteoprogenitors is not affected by the FND treatment, which highly suggest that FNDs are biocompatible and ideal candidates for potential applications in human stem cell research [137].

Low, et al. reported the biocompatibility of thermally-oxidised, aminosilanised porous silicon membranes and their potential to support human ocular cells in vitro and in vivo in the rat eyes. The membranes with pore sizes of 40-60 nm slowly dissolved, but the material could be maintained in tissue culture medium in vitro for at least two weeks without visible degradation. When implanted under the rat conjunctiva, the material did not erode the underlying or overlying tissue. The implant underwent slow dissolution, but remained visible at the operating microscope for over 8 weeks. End-stage histology indicated the presence of a thin fibrous capsule surrounding the implant, but little evidence of any local accumulation of acute inflammatory cells or vascularization. Human lens epithelial cells and primary human corneal explants adhered to the porous silicon membranes, where they remained viable and underwent division. Primary corneal epithelial cells supported on membranes were labelled with a cell tracker dye and implanted under the rat conjunctiva. Seven days later, labelled cells had moved from the membrane into the ocular tissue spaces. A porous silicon membrane may have value as a biomaterial that can support the delivery of cells to the ocular surface and improve existing therapeutic options in patients with corneal epithelial stem cell dysfunction and ocular surface disease [138-139].

Up to date, the effect of nanomaterials on embryonic development is not fully clarified, further researches should focus on investigating their biocompatibility, genotoxicology and advantageous bioactivity with potential application prospects.

\section{Challenges and prospects}

In recent years, application of nanotechnology in stem cells has made great advances, and it is becoming an emerging interdisciplinary field. Stem cell nanotechnology is developing towards imaging, active tracing and controllable regulation of proliferation and differentiation of stem cells. However, like any emerging field, stem cell nanotechnology also faces many challenges. The mechanism of interaction between nanomaterials and stem cells is still not clarified well [140].How nanomaterials and nanostructures to affect the nanomaterials inside stem 
cells to be metabolized are great challenges. How to use current knowledge and principles to fabricate novel multifunctional or homogenous nanostructures, the processing, characterization, interface problems, high quality nanomaterials availability, nanomaterials tailoring, and the mechanisms governing the behavior of these nanoscale composites on the surface of stem cells are also great challenge for present existing techniques. The ips cells were prepared by using HIV virus-based gene delivery system. Using nanomaterialbased gene delivery system to replace virus-based gene delivery system will be a great challenge. However, stem cell nanotechnology shows great attractive prospects and stem cells are developing towards application of generative medicine. We believe that stem cell nanotechnology will be broadly applied in treatment of injuries and degenerative diseases in the near future.

\section{Conclusion}

Stem cell nanotechnology provides a novel chance for stem cells research and development, speeding up the exploration of application of stem cells in generative medicine. Nanomaterials such as quantum dots, fluorescent CNTs and fluorescent magnetic nanoparticles have been used for imaging and tracing, gene or drug delivery, scaffolds for tissue engineering, designed nanostructures have been used to regulate the proliferation and differentiation of stem cells, which will speed up the understanding and controlling the microenvironmental signals, helping to solve the current bottleneck problems of stem cells-based therapy. Although stem cell nanotechnology faces many challenges, marriage of stem cells and nanotechnology have exhibited attractive technological prospects, and will dramatically advance our ability to understand and control stem cell-fate decisions and develop novel stem cell technologies, which will eventually lead to stem cell-based therapeutics for human diseases.

\section{Acknowledgement}

This work is supported by China National 973 Project (No.2010CB933901), National 863 Key Project (No.2007AA022004), National Natural Scientific Fund (No.30672147), and the science and technology foundation of shanghai (No.072112006).

\section{References}

1. Wang Z, Ruan J, Cui D. Advances and Prospect of Nanotechnology in Stem Cells. Nanoscale Research Letter 2009; 4: 593-605.doi:10.1007/s11671-009-9292-z

2. Weissman I L. Stem cells-scientific, medical and political issues. $N$ Eng $J$ Med 2002; 346(8): 1576. doi:10.1056/NEJMsb020693
3. Solanki A, Kim J D, Lee K B. Nanomaterials for biomedical applications. Nanomedicine 2008; 3(4): 567578.doi:10.2217/174358889.3.4.567

4. Aurich I, Mueller L, Aurich H et al. Functional integration of human mesenchymal stem cell-derived hepatocytes into mouse livers.Gut 2007; 56(2): 405415.doi:10.1136/gut.2005.090050

5. $\mathrm{Xu} \mathrm{W} \mathrm{R,} \mathrm{Zhang} \mathrm{X,} \mathrm{Qian} \mathrm{H}$ et al.Mesenchymal stem cells from adult human bone marrow differentiation into a cardiomyocyte phenotype in vitro. Experimental biology and medicine 2002; 229(3): 623-625.

6. Oswald J, Boxberger S, Jorgensen B et al. Mesenchymal stem cells can be differentiated into endothelial cells in vitro. Stem cells 2004; 22(2): 377-379.doi:10.1634/stem cells.22-3-377

7. Gallegos R P, Bolman R M, Card III. Stem cell induced regeneration of myocardium. Surg. Adult. 2008; 3(6): 16571668.

8. Stuart H, Morrison O S et al. Biomedicine: Stem-cell competition. Nature 2002; 418: 25. doi:10.1038/418025a

9. Jiang Y H, Jahagirdar B, Reinhardt R L et al.. Pluripotency of mesenchymal stem cells derived from adult marrow. Nature 2002; 418(1): 41-42.doi:10.1038/nature00870

10. Evans M J, Kaufman M H. Establishment in culture of pluripotential cells from mouse embryos. Nature 1981; 292: 154-157.doi:10.1038/292154a0

11. Heino T J, Hentunen T A. Differentiation of osteoblasts and osteocytes from mesenchymal stem cells. Current stem cell research \& therapy 2008; 2(1): 131137.doi:10.2174/157488808784223032

12. Yu J, Vodyanik M A, Smuga-Otto $\mathrm{K}$ et al. Induced pluripotent stem cell lines derived from human somatic cells. Science 2007; 318: 19171921.doi:10.1126/science. 1151526

13. Takahashi K, Yamanaka S. Induction of pluripotent stem cells from mouse embryonic and adult fibroblast cultures by defined factors. Cell 2006 ; 126 : 663667.doi:10.1016/j.cell.2006.07.024

14. Takahashi $\mathrm{K}$, Tanabe $\mathrm{K}$, Ohnuki $\mathrm{M}$ et al. Induction of pluripotent stem cells from mouse embryonic and adult fibroblast cultures by defined factors. Cell 2007; 131: 861863.doi:10.1016/j.cell.2007.11.019

15. Zhao X, Li W, Lv Z, Liu L, Tong M et al. iPS cells produce viable mice through tetraploid complementation. Nature 2009; 461: 86-88.doi:10.1038/nature08267

16. Metcalf D. Concise Review: Hematopoietic stem cells and tissue stem cells: Current concepts and unanswered questions. Stem Cells 2007; 25: 2390-2394.doi:10.1634/ste mcells.2007-0544

17. Liu S V. iPS Cells: A More Critical Review. Stem Cells and Development. Stem Cells and Development 2008; 17: 391-394.doi:10.1089/scd.2008.0062

18. Liu S V. Are iPS cells really indistinguishable from ES cells? Logical Biology 2007; 7(1):63-65

19. Pera M. Stem cells: A new year and a new era. Nature 2008; 451:135. doi:10.1038/451135a

20. Cui D. Advances and prospects on biomolecules functionalized carbon nanotubes. Journal of 
Nanoscienceand Nanotechnology 2007; 7: 12981314.doi:10.1166/ jnn.2007.654

21. Pan B, Cui D, Ozkan C S et al. DNA-Templated Ordered Array of Gold Nanorods in One and Two Dimensions. Journal of Physical Chemistry C. 2007; 111: 12572-12576. doi:10.1021/jp072335+

22. Pan B, Cui D, Xu P et al. Design of dendrimer modified carbon nanotubes for gene delivery. Chinese Journal of Cancer Reasearch 2007; 19:1-6.doi:10.1007/s11670-007$\underline{0001-0}$

23. Ao L, Gao F, Pan B, He R, Cui D. Fluoroimmunoassay for Antigen Based on Fluorescence Quenching Signal of Gold Nanoparticles. Analytical Chemistry 2006; 78 : 11041107.doi:10.1021/ac05132-3m

24. Cui D, Pan B, Zhang $\mathrm{H}$ et al. Self-assembly of CNTs and Quantum dots for ultrasensitive DNA and antigen detction. Analytical Chemistry $2008 \quad ; \quad 80$ : 79968001.doi:10.1021/ac800992m

25. Washburn N R, Yamada K M, Simon C G et al. Highthroughput investigation of osteoblast response to polymer crystallinity: influence of nanometer-scale roughness on proliferation. Biomaterials 2004 ; 25 : 12151224.doi:10.1016/j.biomaterials.2003.08.043

26. Zhang L, Webster T. Nanotechnology and nanomaterials: Promises for improved tissue regeneration. Nano Today 2009; 4: 66-80.doi:10.1056/NEJMsb020693

27. Clark P, Connolly P, Curtis A S et al. Cell guidance by ultrafine topography in vitro. J. Cell Sci. 1991; 99 (1): 73 77.

28. Jing Y, Moore L R, Williams P S et al. Blood progenitor cell separation from clinical leukapheresis product by magnetic nanoparticle binding and magnetophoresis. Biotechnology and bioengineering 2007; 96: 11391154.doi:10.1002/bit.21202

29. Ohyabu Y, Kaul Z, Yoshioka T et al. Stable and NonDisruptive In Vitro/In Vivo Labeling of Mesenchymal Stem Cells by Internalizing Quantum Dots. Hum Gene Ther 2009; 20: 217-224.doi:10.1089/hum.2008.100

30. Cui D, Zhang H, Wang Z, Toru A, Tetsuya O. Effects of dendrimer-functionalized mult-walled carbon nanotubes on murine embryonic stem cells. ECS Transactions 2008; 13(1): 111-113.doi:10.1149/1.2998536

31. Shi D, Wang W, Lian J, Liu G K, Dong Z Y, Wang L M, Ewing R C. Luminescent Carbon Nanotubes. Adv. Mat. 2006;18: 189-191.doi:10.1002/adma.200501680

32. Biggs M J P, Richards R G, Gadegaard N, Wilkinson C D W, Oreffo R O C, Dalby M J. The use of nanoscale topography to modulate the dynamics of adhesion formation in primary osteoblasts and ERK/MAPK signalling in STRO-1+enriched skeletal stem cells. Biomaterials 2009; 30: 5094-5103. j.biomaterials.2009.05.049

33. Tambralli A, Blakeney B, Anderson J, Kushwaha M, Andukuri A, Dean D, Jun H. A hybrid biomimetic scaffold composed of electrospun polycaprolactone nanofibers and self-assembled peptide amphiphile nanofibers. Biofabrication 2009; 1: 025001.

34. You X, He R, Gao F, Shao J, Pan B, Cui D. Hydrophilic high-luminescent magnetic nanocomposites. Nanotechno logy 2007; 18: 035701.doi:10.1088/0957-4484/18/3/0357 $\underline{01}$

35. Kim D H, Lee S H, Kim K N, Kim K M, Shim I B, Lee Y K. Cytotoxicity of ferrite particles by MTT and agar diffusion methods for hyperthermic application. Journal of Magnetism and Magnetic Materials 2005; 293: 287292.doi:10.1016/j.jmmm.2005.02.07

36. Dong-Hyun K, Se-Ho L, Kyoung-Nam K et al. Cytotoxicity of ferrite particles by MTT and agar diffusion methods for hyperthermic application. J Magn Magn Mater 293: $287-$ 292.doi:10.1016/j.jmmm.2005.02.078

37. Pan B, Cui D, Sheng Y, Ozkan C, Gao F, He R, Li Q, Xu P, Huang T. Dendrimer-Modified Magnetic Nanoparticles Enhance Efficiency of Gene Delivery System. Cancer Research 2007; 67: 17.doi:10.1158/0008-5472.CAN-06$\underline{4762}$

38. Ito $\mathrm{A}$, Ino $\mathrm{K}$, Kobayashi $\mathrm{T}$, Honda $\mathrm{H}$. RGD peptideconjugated magnetite cationic liposomes on cell growth and cell sheet harvesting. Biomaterials 2005; 26: 61856193.doi:10.1016/i.biomaterials.2005.03.039

39. Sincai M, Ganga D, Ganga M Argherie D, Bica D. Antitumor effect of magnetite nanoparticlesin cat mammary adenocarcinoma. J Magn Magn Mater 2005; 293(2): 43841.doi:10.1016/j.jmmm.2005.02.074

40. Morishita M, Nakagami H, Morishita $\mathrm{R}$ et al. Magnetic nanoparticleswith surface modification enhanced gene delivery of HVJ-E vector. Biochem Biophys Res Commun 2005; 334: 1121-1126.doi:10.1016/j.bbrc.20 05.06 .204

41. Medintz I L, Uyeda H T, Goldman E R, Mattoussi H. Quantum dot bioconjugates for imaging, labelling and sensing. Nature Mater. 2005; 4: 435446.doi:10.1038/nmat1390

42. Sykova E, Jendelova P. Magnetic resonance tracking of transplanted stem cells in rat brain and spinal cord. Neurodegenerative Diseases 2006; 3: 62 67.doi:10.1159/000092095

43. Yang D, Cui D. Advances and Prospects of Gold Nanorods. Chem. Asian J. 2008; 3: 2010 2020.doi:10.1002/asia.200800195

44. Bakalova R, Zhelev Z, Aoki I, Kanno I. Designing quantum-dot probes. Nature Photonics 2007; 1(9): 487 488. doi:10.1038/nphoton.2007.150

45. Hoshino A, Fujioka K, Manabe N, Yamaya S Goto Y, Yasuhara M, Yamamoto K. Simultaneous multicolor detection system of the single-molecular microbial antigen with total internal reflection fluorescence microscopy. Microbiology and Immunology 2005; 49: 461-470.

46. Huang X Y, Li L, Qian H F, Dong C Q, Ren C J. A resonance energy transfer between chemiluminescent donors and luminescent quantum-dots as acceptors (CRET). Angew. Chem. Int. Ed. 2006 ; 45 : 5140-5143. doi:10.1002/anie.200601196

47. Han M, Gao X, Su J Z, Nie S M. Quantum-dot-tagged microbeads for multiplexed optical coding of biomolecules. Nature Biotechnol. 2001; 19: 631-635. doi:10.1038/ $\underline{90228}$

48. Sykova E, Jendelova P. Magnetic resonance tracking of 
transplanted stem cells in rat brain and spinal cord Neurodegener Dis. 2006; 3: 62-67. doi:10.1159/0000 $\underline{92095}$

49. Maxwell D J, Bonde J, Hess D A et al. Fluorophore Conjugated Iron Oxide Nanoparticle Labeling and Analysis of Engrafting Human Hematopoietic Stem Cells. Stem cells 2008; 26: 517-524.doi:10.1634/stemcells.2007-0016

50. Berry C C, Harianawalw H, Loebus J, Oreffo R O C, de la Fuente J. Enhancement of Human Bone Marrow Cell Uptake of Quantum Dots using Tat Peptide. Current Nanoscience 2009; 5: 390-395.

51. Coyne T M, Marcus A J, Woodbury D et al. Marrow Stromal Cells Transplanted to the Adult Brain are Rejected by an Inflammatory Response and Transfer Donor Labels to Host Neurons and Glia. Stem cells 2006; 24 : 2483 2492.doi:10.1634/stemcells.2006-0174

52. Jendelová P, Herynek V, Urdzíková L et al. Magnetic resonance tracking of transplanted bone marrow and embryonic stem cells labeled by iron oxide nanoparticles in rat brain and spinal cord. Journal of neuroscience research 2004; 76: 232-243. doi:10.1002/jnr.20041

53. Coyne T M, Marcus A J, Reynolds K et al. Disparate host response and donor survival after the transplantation of mesenchymal or neuroectodermal cells to the intact rodent brain. Transplantation. 2007;84(11):1507-1516

54. Ju S, Teng G, Zhang $Y$ et al. In vitro labeling and MRI of mesenchymal stem cells from human umbilical cord blood. Magn Reson Imaging 2006 ; 24 : 611-617. doi:10.1016/j.mri.2005.12.017

55. Terrovitis J, Stuber M, Youssef A et al. Magnetic Resonance Imaging Overestimates Ferumoxide-Labeled Stem Cell Survival after Transplantation in the Heart. Circulation. $2008 ; 117$ : 1555-1562. doi:10.1161/CIRC ULATIONAHA.107.732073

56. Zuzana B, Daniel J, Klara Z et al. Labeling of Pancreatic Islets With Iron Oxide Nanoparticles for In Vivo Detection With Magnetic Resonance. Transplantation 2008; 85 : 155-159.

57. Castano H, O"Rear E A, McFetridge P S et al. Polypyrrole thin films formed by admicellar polymerization support the osteogenic differentiation of mesenchymal stem cells. Macromol Biosci.2004; 4 : 785-794. doi:10.1002/mab i. 200300123

58. San Román J A, Fernández-Avilés F. The role of noninvasive imaging techniques in the assessment of stem cell therapy after acute myocardial infarction. Nature Clinical Practice Cardiovascular Medicine 2006; 3 : S38-S41.doi:10.1038/ncpcardio0448

59. Evgenov N V, Medarova Z, Pratt J et al. In Vivo Imaging of Immune Rejection in Transplanted Pancreatic Islets. Diabetes 2006; 55: 2419-2428.doi:10.2337/db06-0484

60. He R, You X, Shao J, Gao F, Pan B, Cui D. Core/shell fluorescent magnetic silica-coated composite nanoparticles for bioconjugation. Nanotechnology 2007; 18 : 315601.doi:10.1088/0957-4484/18/31/315601

61. Noh M S, Jun B H, Kim S, Kang H, Woo M, MinaiTehrani A, Kim J E, Kim J, Park J, Lim H, Park S C, Hyeon T, Kim Y K, Jeong D H, Lee Y S, Cho M. Magnetic surface-enhanced Raman spectroscopic (M-SERS) dots for the identification of bronchioalveolar stem cells in normal and lung cancer mice. Biomaterials 2009 ; 30: 3915-25.

62. Cui D, Zhang H, Wang Z, Asahi T, Osaka T. Effects of Dendrimer-Functionalized Multi-walled Carbon Nanotubes on Murine stem cells. ECS Transactions 2008 ; 13 : 111116.

63. Park I H, Lerou P H, Zhao R, Huo H, Daley G Q. Generation of human-induced pluripotent stem cells. Nature Protoc. 2008 ; 3 : 1180-1186. doi:10.1038/ nprot.2008.92

64. Ruiz-Cabello J, Walczak P, Kedziorek D, Chacko V, Schmieder A, Wickline S, Lanza G, Bulte J. In Vivo "Hot Spot" MR Imaging of Neural Stem Cells Using Fluorinated Nanoparticles. Magnetic Resonance in Medicine 2008; 60: 1506-1511.

65. Liu K, Wang C, Cheng C, Chao J. Endocytic carboxylated nanodiamond for the labeling and tracking of cell division and differentiation in cancer and stem cells. Biomaterials 2009; 30: 4249-59.

66. Solanki A, Kim J D, Lee K B. Nanotechnology for regenerative medicine: nanomaterials for stem cell imaging. Nanomedicine, 2008 ; 3: 567-578.

67. Nakatsuji N, Nakajima F, Tokunaga K. HLA-haplotype banking and iPS cells. Nature Biotechnol. 2008; 26: 739 740.doi:10.1038/nbt0708-739

68. Wood S A, Allen N D, Rossant J, Auerbach A, Nagy A. Non-injection methods for the production of embryonic stem cell-embryo chimeras. Nature 1993; 365: 87-89. doi: $10.1038 / 365087 \mathrm{a} 0$

69. Cui D, Tian F, Coyer C R et al. Effects of as-myc conjugated single-walled carbon nanotubes on HL-60 cells. J. Nanosci Nanotechnol. 2007 ; 7 : 1639-1646. doi:10.1166/inn.2007.348

70. Kam SW, Liu Z, Dai H. Carbon nanotubes as intracellular transporters for proteins and DNA: an investigation of the uptake mechanism and pathway. Angew. Chem. Int. Ed. 2006; 45: 577-581.doi:10.1002/anie.200503389

71. Jimenez-Contreras R, Chief Editor. Nanotechnology Research Developments, Chapter one, Pan, B. and Cui, D. Advance and application prospect of Dendrimers. Springer Press.2008; 7-95.

72. Lee J W, Kim B K, Kim H, Han S C, Shin W S, Jin S H. Macromolecules 2006; 39: 2418-2420.

73. Pan B, Cui D, Shen Y, Ozkan C S, Gao F, He R, Li Q, $\mathrm{Xu} P$, Huang T. Dendrimer-Modified Magnetic Nanoparticles Enhance Efficiency of Gene Delivery System. Cancer Research 2007 ; 67 : 8156-8163 doi:10.1158/0008-5472.CAN-06-4762

74. Pan B, Cui D, Xu P, Huang T, Li Q, He R, Gao F. Enhancement of cellular uptake of dendrimer-modified Quantum dots. J. Biomed. Pharm. Eng. 2007; 1: 13-16.

75. Han S W, Nakamura C, Obataya I et al. A molecular delivery system by using AFM and nanoneedle. Biosens Bioelectron. 2005; 20 : 2120-2125. doi:10.1016/j.bio s.2004.08.023

76. Bharali D, Klejbo, I, Stachowial E K et al. Organically modified silica nanoparticles: A nonviral vector for in vivo 
gene delivery and expression in the brain. Proc. Natl. Acad. Sci. USA. 2005 ; 102 : 11539-11544. doi:10.1073/pn as. 0504926102

77. Obataya I, Nakamura C, Han S W et al. Nanoscale operation of a living cell using an atomic force microscope with a nanoneedle. Nano Lett 2005; 5 : 27-30. doi:10.1021/n10485399

78. Han S W, Nakamura C, Obataya I et al. A molecular delivery system by using AFM and nanoneedle. Biosens Bioelectron.2005; 20: 2120-2125.

79. Green J J, Zhou B Y, Mitalipova M M, Beard C, Langer R, Jaenisch R, Anderson D. Nano Letters 2008; 8: 31263130.doi:10.1021/nl8012665

80. Soenen SJH, Hodenius M, De Cuyper M. Magnet oliposomes: versatile innovative nanocolloids for use in biotechnology and biomedicine. Nanomedicine 2009; 4: 177-191.doi:10.2217/17435889.4.2.177

81. Warheit D B, Laurence B R, Reed K L, Roach D H, Reynolds G A, Webb T R. Comparative pulmonary toxicity assessment of single-wall carbon nanotubes in rats. Toxicol Sci. 2004; 77: 117-125.doi:10.1093/toxsci/kfg228

82. Cui D, Tian F, Kong Y, Igor T, Gao H. Effect of single wall carbon nanotubes on polymerase chain reaction. Nanotechnology, 2004; 15: 154-158.doi:10.1088/0957$\underline{4484 / 15 / 1 / 030}$

83. Gao H, Kong Y, Cui D, Ozkan C S. Spontaneous insertion of DNA oligonucleotides into carbon nanotubes. Nano Lett.2003; 3: 471-473.doi:10.1021/n1025967a

84. Guo Z J, Sadler P J, Tsang S C. Immobilization and visualization of DNA and proteins on carbon nanotubes. Adv. Mater. 1998; 10: 701-703.doi:10.1002/(SICI)15214095(199806)10:9<701::AID-ADMA701>3.0.CO;2-4

85. Cui D, Ozkan C S, Ravindran S, Kong Y, Gao H. Encapsulation of Pt-labelled DNA molecules inside carbon nanotubes. Mechanics and Chemistry of Biological System.2004; 1: 113-121.

86. Hafner J H, Cheung C L, Woolley A T, Lieber C M. Structural and functional imaging with carbon nanotube AFM probes. Progress in Biophysics \& Molecular Biology 2001; 77: 73-110.doi:10.1016/S0079-6107(01)00011-6

87. Liu Y, Wu D, Zhang W, Jiang X, He C, Chung T S, Goh S $\mathrm{H}$, Leong K W. Polyethylenimine-Grafted Multiwalled Carbon Nanotubes for Secure Noncovalent Immobilization and Efficient Delivery of DNA. Angew. Chem. Int. Ed. 2005; 44: 4782-4785.doi:10.1002/ani e.200500042

88. Pantarotto D, Singh R, McCarthy D, Erhardt M, Briand J, Prato M, Kostarelos K, Bianco A. Functionalized Carbon Nanotubes for Plasmid DNA Gene Delivery. Angew. Chem. Int. Ed. 2004; 43: 5242.doi:10.1002/anie.200460437

89. Lu Q, Moore J M, Huang G, Mount A S, Rao A M, Larcom, L L, Ke P C. RNA Polymer Translocation with SingleWalled Carbon Nanotubes. Nano Lett. 2004; 4: 2473-2475.

90. Kam N W S, Dai H. Carbon Nanotubes as Intracellular Protein Transporters: Generality and Biological Functionality.J. Am. Chem. Soc. 2005; 127: 60216022.doi:10.1021/ja050062v

91. Kam N W S, Jessop T C, Wender P A, Dai H. Nanotube Molecular Transporters: Internalization of Carbon
Nanotube-Protein Conjugates into Mammalian Cells. $\mathrm{J}$. Am Chem. Soc. 2004; 126: 6850.doi:10.1021/ja0486059

92. Cui D, Tian F, Coyer S R, Wang J, Gao F, He R, Pan B, Zhang Y. Effects of antisense-myc-conjugated singlewalled carbon nanotubes on HL-60 cells. J. Nanoscience \& Nanotechnology $\quad 2007 ; \quad 7: \quad 1639-1642$.doi:10.1166/in n.2007.348

93. Cui D, Tian F, Ozkan C S, Wang M, Gao H. Effects of single wall carbon nanotubes on HEK293 cells. Toxicology Letter 2005; 155: 77-94.doi:10.1016/j.toxlet.20 04.08.015

94. Crouse C A, Maruyama B, Colorado R J, Back T, Barron A R. Growth, new growth, and amplification of carbon nanotubes as a function of catalyst composition. $J \mathrm{Am}$ Chem Soc 2008; 130: 7946-7954.doi:10.1021/ja $\underline{800233 \mathrm{~b}}$

95. Zhou G S, Su Z Y, Cai Y R, Liu Y K et al. Different effects of nanophase and conventional hydroxyapatite thin films on attachment, proliferation and osteogenic differentiation of bone marrow derived mesenchymal stem cells. Biomed Mater Eng. 2007; 17: 387-395

96. Gelain F, Bottai D, Vescovi A et al. Designer SelfAssembling Peptide Nanofiber Scaffolds for Adult Mouse Neural Stem Cell 3-Dimensional Cultures. PLoS One 2006; 1: 119.doi:10.1371/journal.pone.0000119

97. $\mathrm{Lu} \mathrm{Y,} \mathrm{Chen} \mathrm{S} \mathrm{C.} \mathrm{Micro} \mathrm{and} \mathrm{nano-fabrication} \mathrm{of}$ biodegradable polymers for drug delivery. Advanced drug delivery reviews 2004; 56: 1621-1633.doi:10.10 16/j.addr.2004.05.002

98. Gelain F. Novel opportunities and challenges offered by nanobiomaterials in tissue engineering. International Journal of Nanomedicine 2008; 3: 415-424.

99. Park S Y, Namgung S, Kim B, Im J, Kim J Y, Sun K, Lee K B, Nam J, Park Y, Hong S. Carbon nanotube monolayer patterns for directed growth of mesenchymal stem cells. Adv. Mater. 2007; 19(2): 2530-2532.doi:10.1002/adm a.200600875

100. Dalby M J, Riwhle M O, Johnstone H J H et al. Polymerdemixed nanotopography: Control of fibroblast spreading and proliferation. Tissue Eng. 2002; 8: 10991108.doi:10.1089/107632702320934191

101. Adams G B, Chabner K T, Alley I R et al. Stem cell engraftment at the endostelial niche is specified by the calcium-sensing receptor. Nature. 2006; 439: 599-603. doi:10.1038/nature04247

102. Owen G R, Jackson J, Chehroudi B et al. A PLGA membrane controlling cell behaviour for promoting tissue regeneration. Biomaterial 2005; 26: 7447-7456. doi:10.1016/j.biomaterials.2005.05.055

103. Wilson C J, Richard B E, Clegg E et al. Mediation of biomaterial-cell interactions by adsorbed proteins: A review. Tissue engineering 2005; 11: 1-18.doi:10.1089/ten.20 $\underline{05.11 .1}$

104. Haack B, Reboud J, Combe S et al. A "DropChip" cell array for DNA and siRNA transfection combined with drug screening. Nanobiotechnology 2005; 1: 1551-1286.

105. Fan Y W, Cui F Z, Hou S P et al. Culture of neural cells on silicon wafers with nano-scale surface topograph. $J$ Neurosci Methods 2002; 120: 17 - 23.doi:10.1016/S0165- 
0270(-02)00181-4

106. Edgar D, Kenny S, Almond S et al. Topography, stem cell behaviour, and organogenesis. Pediatric surgery international. 2004; 20: 737-740.doi:10.1007/s00383-004$\underline{1288-2}$

107. Teixeira A I, Abrams G A, Bertics P J et al. Epithelial contact guidance on well-defined micro- and nanostructured substrates. J. Cell Sci. 2003; 15:18811892.doi: $10.1242 /$ jcs. 00383

108. Castano H, O'Rear E A, McFetridge P S et al. Polypyrrole thin films formed by admicellar polymerization support the osteogenic differentiation of mesenchymal stem cells. Macromol Biosci. 2004; 4: 785794.doi:10.1002/mabi.200300123

109. Clark P, Connolly P, Curtis A S et al. Cell guidance by ultrafine topography in vitro. J. Cell Sci.1991; 99: 73-77.

110. Thorvaldsson A, Stenhamre H, Gatenholm $\mathrm{P}$ et al. Electrospinning of highly porous scaffolds for cartilage regeneration. Biomacromolecules 2008; 9: 10441049.doi: $10.1021 / \mathrm{bm} 701225 \mathrm{a}$

111. Moroni L Schotel R, Hamann D et al. 3D Fiber-deposited electrospun integrated scaffolds enhance cartilage tissue formation. Advanced Functional Materials 2007; 10: 53-60.

112. Li Z S, Zhang M Q. Chitosan-alginate as scaffolding material for cartilage tissue engineering. Journal of Biomedical Materials Research Part A. 2008; 74: 485-493.

113. Tysseling-Mattiace V M, Sahni V, Niece K L et al. Selfassembling nanofibers inhibit glial scar formation and promote axon elongation after spinal cord injury. $J$ Neurosci 2008; 28 : 3814-3823.doi:10.1523/JNEUROSC I.0143-08.2008

114. Silva G A, Czeisler C, Niece K L et al. Selective differentiation of neural progenitor cells by high-epitope density nanofibers. Science 2004; 303: 13521355.doi:10.1126/science. 1093783

115. Modi G, Pillay V, Choonara Y, Ndesendo V, Naidoo D. Nanotechnological applications for the treatment of neurodegenerative disorders. Progress in Neurobiology2009; 88: 272-285.doi:10.1016/j.pneurobi $\underline{0.2009 .05 .002}$

116. Bakeine G J, Ban J, Grenci G, Pozzato A, Dal Zilio S, Prasciolu M, Businaro L, Tormen M, Ruaro M. Design, fabrication and evaluation of nanoscale surface topography as a tool in directing differentiation and organisation of embryonic stem-cell-derived neural precursors. Microelectronic Engineering 2009; 86: 1435 1438.doi:10.1016/j.mee.2009.01.032

117. Jain K K. Neuroprotection in traumatic brain injury. Drug Discovery Today 2009; 13: 1082-1089. doi:10.1016/j.dru dis.2008.09.006

118. Xie J, Willerth S M, Li X, Macewan M R, Rader A, Sakiyama-Elbert S E, Xia Y. The differentiation of embryonic stem cells seeded on electrospun nanofibers into neural lineages. Biomaterials 2009; 30: 354-62.doi:10.10 $\underline{\text { 16/j.biomaterials.2008.09.046 }}$

119. Orive G, Anitua E, Luis Pedraz J, Emerich D F. Biomaterials for promoting brain protection, repair and regeneration. Nature Reviews Neuroscience 2009; 10: 682-
U47. doi:10.1038/nrn2685

120. Kapadia M R, Chow L W, Tsihlis N D et al. Nitric oxide and nanotechnology: a novel approach to inhibit neointimal hyperplasia. $J$ Vasc Surg 2008; 47: 173182.doi:10.1016/j.jvs.2007.09.005

121. Harding S E, Ali N N, Brito-Martins M, Gorelik J. The human embryonic stem cell-derived cardiomyocyte as a pharmacological model. Pharmacol Ther 2007; 113: 341353.doi:10.1016/i.pharmthera.2006.08.008

122. Spadaccio C, Rainer A, Trombetta M, Vadala G, Chello M, Covino E, Denaro V, Toyoda Y, Genovese J. Poly-1-Lactic Acid/Hydroxyapatite Electrospun Nanocomposites. Induce Chondrogenic Differentiation of Human MSC. Annals of Biomedical Engineering 2009; 37: 1376-1389.

123. Aoki K, Usui Y, Narita N, Ogiwara N et al. A thin carbonfiber web as a scaffold for bone-tissue regeneration. Small 2009; 5: 1540-1546.

124. Biggs M J P, Richards R G, Gadegaard N, Wilkinson C D W, Oreffo R O C, Dalby M J. The use of nanoscale topography to modulate the dynamics of adhesion formation in primary osteoblasts and ERK/MAPK signalling in STRO-1+enriched skeletal stem cells. Biomaterials 2009; 30: 5094-5103.

125. Biggs M J P, Richards R G, Gadegaard N, McMurray R, Affrossman S, Wilkinson C D W, Oreffo R O C, Dalby M $\mathrm{J}$. Interactions with nanoscale topography: Adhesion quantification and signal transduction in cells of osteogenic and multipotent lineage. Journal of Biomedical Materials Research Part A. 2009; 91A: 195-208.

126. Biggs M J P, Richards R G, McFarlane S, Wilkinson C D W, Oreffo R O C, Dalby M J. Adhesion formation of primary human osteoblasts and the functional response of mesenchymal stem cells to $330 \mathrm{~nm}$ deep microgrooves. Journal of The Royal Society Interface 2008; 5: 12311242.

127. Bianco A, Di Federico E, Moscatelli I, Camaioni A, Armentano I, Campagnolo L, Dottori M, Kenny J M, Siracusa G, Gusmano G. Electrospun poly(epsiloncaprolactone)/Ca-deficient hydroxyapatite nanohybrids: Microstructure, mechanical properties and cell response by murine embryonic stem cells. Materials Science \& Engineering C- Materials for Biological Applications 2009; 29: 2063-2071.

128. Smith L A, Liu X, Hu J, Ma P X. The influence of threedimensional nanofibrous scaffolds on the osteogenic differentiation of embryonic stem cells. Biomaterials 2009; 30, 2516-2522. doi:10.1016/j.biomaterial s.2009.01.009

129. Variola F, Vetrone F, Richert L, Jedrzejowski P, Yi J, Zalzal S, Clair S, Sarkissian A, Perepichka D, Wuest J, Rosei F, Nanci A. Improving Biocompatibitity of Implantable Metals by Nanoscale Modification of Surfaces: An Overview of Strategies, Fabrication Methods, and Challenges. Small 2009; 5: 996-1006.

130. .Huang D M, Hsiao J, Chen Y, Chien L, Yao M, Chen Y, Ko B, Hsu S, Tai L et al. The promotion of human mesenchymal stem cell proliferation by superparamagnetic iron oxide nanoparticles. Biomaterials 2009; 30: 3645 51 . 
131. Tambralli A, Blakeney B, Anderson J, Kushwaha M, Andukuri A, Dean D, Jun H. A hybrid biomimetic scaffold composed of electrospun polycaprolactone nanofibers and self-assembled peptide amphiphile nanofibers. Biofabrication 2009; 1: 025001

132. Yang W, Hsu M, Lin M, Chen Z, Chen L, Huang H. Nano/submicron-scale $\mathrm{TiO}_{2}$ network on titanium surface for dental implant application. Journal of Alloys and Compounds 2009; 479: 642-647.

133. Heo S J, Kim S E, Wei J, Kim D H, Hyun Y T, Yun H S, Kim H K, Yoon T R, Kim S H, Park S A, Shin J W, Shin J W. In Vitro and Animal Study of Novel NanoHydroxyapatite/Poly(epsilon-Caprolactone) Composite Scaffolds Fabricated by Layer Manufacturing Process. Tissue Engineering Part A. 2009; 15: 977-989.

134. Elsaesser A, Barnes C, McKerr G, Howard C, Lynch I, Dawson K, Piersma A. In vitro developmental toxicity test detects inhibition of stem cell differentiation by silica nanoparticles. Toxicology and Applied Pharmacology 2009; 240: 108-116.

135. Deng X, Chen W, Wang Y, Wu M, Zhang H, Zheng J. Nanosized zinc oxide particles induce neural stem cell apoptosis. Nanotechnology 2009; 20: 115101.

136. Singh N, Manshian B, Jenkins G J S, Griffiths S M, Williams P M, Maffeis T G G, Wright C J, Doak S H. NanoGenotoxicology: The DNA damaging potential of engineered nanomaterials. Biomaterials 2009; 30: 38913914.
137. Vaijayanthimala V, Tzeng Y, Chang H, Li C. The biocompatibility of fluorescent nanodiamonds and their mechanism of cellular uptake. Nanotechnology 2009; 20: 425103.

138. Lin H, Ling M, Lin Y. High strength and low friction of a PAA-alginate-silica hydrogel as potential material for artificial soft tissues. Journal of Biomaterials Science, Polymer Edition 2009; 20: 637-652.

139. Kittler S, Greulich C, Koeller M, Epple M. Synthesis of PVP-coated silver nanoparticles and their biological activity towards human mesenchymal stem cells. Materialwissenschaft und Werkstofftechnik 2009; 40: 258264.

140. Low S P, Voelcker N H, Canham L T, Williams K A. The biocompatibility of porous silicon in tissues of the eye. Biomaterials 2009; 30: , 2873-2880.

141. Daxiang Cui, Chapter 7. Cytotoxicity and potential mechanism of nanomaterials. Nanotoxicology Yuliang Zhao, Hari Singh Nalwa, editor in chief. American Scientific Publishers 2007; 103-111.

Received 8 January, 2010; accepted 10 February, 2010; published online 5 March, 2010.

Copyright: (c) $2010 \mathrm{~J}$. Ji et al. This is an open-access article distributed under the terms of the Creative Commons Attribution License, which permits unrestricted use, distribution and reproduction in any medium, provided the original author and source are credited. 